Research Paper

\title{
Network pharmacology reveals the potential mechanism of Baiying Qinghou decoction in treating laryngeal squamous cell carcinoma
}

\author{
Kun Gao ${ }^{1,2}$, Yanan Zhu ${ }^{3}$, Hui Wang ${ }^{4}$, Xianwei Gong ${ }^{5}$, Zhiyong Yue ${ }^{1,2}$, Aiai Lv ${ }^{3}$, Xuanchen Zhou ${ }^{1,2}$ \\ ${ }^{1}$ Department of Otorhinolaryngology Head and Neck Surgery, Shandong Provincial Hospital Affiliated to Shandong \\ First Medical University, Jinan 250021, Shandong, China \\ ${ }^{2}$ Department of Otorhinolaryngology Head and Neck Surgery, Shandong Provincial Hospital Affiliated to Shandong \\ University, Jinan 250021, Shandong, China \\ ${ }^{3}$ Department of Internal Medicine, Shandong Provincial Chest Hospital Affiliated to Shandong University, Jinan \\ 250013, Shandong, China \\ ${ }^{4}$ Department of Ultrasound, The Fifth People's Hospital of Jinan, Jinan 250022, Shandong, China \\ ${ }^{5}$ Department of Pharmacy, Shandong Provincial Hospital Affiliated to Shandong First Medical University, Jinan \\ 250021, Shandong, China
}

Correspondence to: Xuanchen Zhou, Aiai Lv; email: xuanchen zhou@163.com, https://orcid.org/0000-0001-7072-6577; 15169062809@163.com, https://orcid.org/0000-0002-7043-1047

Keywords: Baiying Qinghou decoction, laryngeal squamous cell carcinoma, molecular docking, network pharmacology, protein-protein interaction

Received: June 24, 2021

Accepted: November 22, 2021

Published: December 20, 2021

Copyright: (C) 2021 Gao et al. This is an open access article distributed under the terms of the Creative Commons Attribution License (CC BY 3.0), which permits unrestricted use, distribution, and reproduction in any medium, provided the original author and source are credited.

\section{ABSTRACT}

Context: Baiying Qinghou as a traditional Chinese medicine decoction shows anticancer property on laryngeal squamous cell carcinoma. However, little is known about the precise mechanism of Baiying Qinghou detection against laryngeal squamous cell carcinoma.

Objective: This study was aimed to explore potential mechanism of therapeutic actions of Baiying Qinghou decoction on laryngeal squamous cell carcinoma.

Materials and Methods: The active chemical components of Baiying Qinghou decoction were predicted, followed by integrated analysis of network pharmacology and molecular docking approach. The network pharmacology approach included target protein prediction, protein-protein interaction network construction and functional enrichment analysis.

Results: Sitosterol and quercetin were predicted to be the overlapped active ingredients among three Chinese herbs of Baiying Qinghou decoction. The target proteins were closely associated with response to chemical, response to drug related biological process and cancer related pathways such as PI3K-Akt signaling, HIF-1 signaling and Estrogen signaling pathway. The target proteins of TP53, EGFR, PTGS2, NOS3 and IL1B as the key nodes in PPI network were cross-validated, among which EGFR, IL1B, NOS3 and TP53 were significantly correlated with the prognosis of patients with laryngeal squamous cell carcinoma. Finally, the binding modes of EGFR, IL1B, NOS3 and TP53 with quercetin were visualized.

Discussion and Conclusion: Quercetin of Baiying Qinghou decoction showed therapeutic effect against laryngeal squamous cell carcinoma by regulating TP53, EGFR, NOS3 and IL1B involved with drug resistance and PI3K-AKT signaling pathway. TP53, EGFR, NOS3 and IL1B may be the candidate targets for the treatment of laryngeal squamous cell carcinoma. 


\section{INTRODUCTION}

Head and neck cancer (HNC) is the seventh most common malignant tumor worldwide and occurs in nasopharynx, larynx, and thyroid [1, 2]. Head and neck squamous cell carcinoma (HNSCC) accounts for over 90\% cases of head and neck cancer (HNC) and mainly derives from the mucosal surfaces of the upper aerodigestive tract [3]. Laryngeal squamous cell carcinoma (LSCC) represents the second most common histological subtypes of $\mathrm{HNC}$ with an increasing incidence rate [4]. Patients with LSCC are usually diagnosed at a late clinical stage and the survival rate is lower due to regional or distant metastases. Thus, LSCC has caused noticeable medical and economic burden worldwide.

Currently, several mainstream options against LSCC include surgery, radiotherapy, chemotherapy and chemo-radiotherapy [5]. However, the overall survival of patients with LSCC has not been remarkably improved because of chemotherapy or drug resistance and undesired effects. Traditional Chinese medicines (TCM) has been considered as an attractive alternative therapy for conquering cancers in China [6]. TCM focuses on restoring body balance and boosting immunity by the synergistic effects of various active ingredients [7]. Some Chinese herbs have been frequently utilized for the treatment of different diseases, such as cardiovascular diseases, diabetes and caners [8-10]. A recent research highlights that erchen plus huiyanzhuyu decoction can inhibit the growth of laryngeal carcinoma by modulating STAT3/cyclin D1 signaling pathway [11]. TCM exerts promising therapeutic effect on various malignant tumors.

Network pharmacology is proposed by Hopkins et al. and aims to explore the multilevel interactions of diseases, genes, and drugs as a whole [12]. This systems pharmacology is based on systems biology, computational biology and omics theory to evaluate the therapeutic effects of Chinese medicines on several diseases [13]. Gao et al. indicate that 8 herbs regulate multiple hepatocellular carcinoma-related genes and are strongly associated with prognosis by a network pharmacology approach [14]. Huang et al. suggest Huanglian Jiedu decoction has therapeutic roles in cancers such as hepatocellular carcinoma by building the herb-compound, compound-protein, proteinpathway, and gene-disease networks [15]. Notably, Bai Ying Qing Hou (BYQH) decoction is a Chinese medicinal formula and widely used for the treatment of LSCC in China, which is primarily composed of five key traditional Chinese herbs: Solanum lyratum thumb (30 g), Scutellaria barbata (24 g), Duchesnea indica (24 g), Solanum nigrum (30 g), and Actinidia chinensis planch (30 g). However, the pharmacological mechanism of BYQH decoction in the treatment of LSCC has not been clarified.

In this study, we attempted to explore the mechanism of BYQH decoction in the treatment of LSCC by network pharmacology analysis. First, the key active chemical constituents and their target proteins of $\mathrm{BYQH}$ decoction were screened. Then, the Gene Ontology (GO) and Kyoto Encyclopedia of Genes and Genomes (KEGG) pathway analyses of gene targets were carried out. Besides, protein-protein interaction (PPI) and target proteins were cross-validated followed by survival analysis. Finally, molecular docking was used to identify the binding mode of key active ingredients and target proteins of $\mathrm{BYQH}$ decoction.

\section{MATERIALS AND METHODS}

\section{Screening active constituents of BYQH decoction}

The traditional Chinese medicine systems pharmacology database (TCMSP) is an herbal repository and provides the system information about Chinese herbal medicines [16]. The absorption, distribution, metabolism, and excretion (ADME) system has been successfully used to evaluate the pharmacokinetics characteristics of chemical compounds [17, 18]. Herein, the chemical composition of five key components of $\mathrm{BYQH}$ decoction was firstly searched from TCMSP, mainly including the number of the pharmaceutical ingredient, molecule name, molecular weight, lipid-water partition coefficient, the number of hydrogen-bonding donor or acceptor, oral bioavailability (OB), blood brain barrier, Caco-2 permeability (Caco-2), drug-likeness (DL), and half-life (HL). OB $\geq 30 \%$ and Caco- $2 \geq-0.4$ indicate good OB and permeability of molecules. The mean DL value of drugs collected in database is 0.18 . Then, active chemical compounds were screened in ADME system according to the criteria of $\mathrm{OB} \geq \mathrm{O} 30 \%, \mathrm{DL} \geq$ 0.18 and Caco- $2 \geq-0.4$ according the previous description [19].

\section{Screening protein targets of active chemical compounds}

TCMSP and DrugBank (https://www.drugbank.ca/) databases can predict the relationships between drugs and corresponding targets. Moreover, DrugBank database provides the detailed information on experimental and investigational drugs [20]. The active chemical compounds were subjected to TCMSP and DrugBank databases to search their potential targets. Then, the target proteins were mapped to corresponding gene symbols using string database. For those proteins that did not map to any gene symbols, they were 
manually retrieved by Universal Protein (UniProt) database to map to corresponding gene symbols. These potential gene targets were used for following analysis.

\section{Functional enrichment analysis of target genes}

To investigate the biological function of the target genes, the gene ontology (GO) functional annotation and Kyoto Encyclopedia of Genes and Genomes (KEGG) pathway enrichment analyses were carried out. There are three categories for GO terms, including biological process (BP), cellular component (CC) and molecular function (MF). Gene symbols were input into string database. The parameters were set as the default values. The significantly enriched GO and pathway terms with $p<0.05$ were collected. Then, the top $10 \mathrm{GO}$ terms in each category and top 10 significant pathways were visualized in bubble chart by using $\mathrm{R}$ language.

\section{Target protein-protein interaction (PPI) analysis}

The underlying relationships among target proteins were analyzed based on the string database according to the default parameters [21]. The Cytoscape software was used to construct and visualize the PPI network. Following this, the topological characteristics of the PPI network were also evaluated. The node degree (connectivity) was calculated.

\section{Cross-validation of target proteins by the database retrieval}

DisGeNET is a versatile platform that comprehensively collects human gene-disease associations (over 380,000 associations between more than 16,000 genes and 13,000 diseases) for the validation of computationally predicted genes for human diseases [22, 23]. In this study, the genes related to LSCC were firstly searched from this database using "carcinoma of larynx" as the keyword. Phenopedia database also provides systematical genetic association studies and summarizes the information about the association between genes studied and a particular disease. Therefore, the known genes associated with LSCC were obtained by retrieving Phenopedia database with the keyword of "laryngeal neoplasms". Subsequently, the overlapping genes among target genes of BYQH decoction, LSCCrelated genes in DisGeNET or Phenopedia database were extracted by jvenn tool $[24,25]$. These genes may be associated with the therapeutic effects of $\mathrm{BYQH}$ decoction against LSCC.

\section{Survival analysis of candidate genes}

Firstly, expression profiles of HNSCC samples deposited in the Cancer Genome Atlas (TCGA) dataset were downloaded from UCSC Xena (https://xenabrowser.net/datapages/). Based on the clinical information, the HNSCC samples were selected according to following criteria: 1) samples were primary tumor tissues and the primary site was at the larynx; 2) the clinical information of samples with regard to TNM stage, clinical stage, grade and followup were complete; 3) the samples without survival time were deleted. Finally, a total of 105 laryngeal cancer samples were retained for the next prognostic analysis.

To investigate whether key candidate genes are associated with prognosis of patients with laryngeal cancer, the survival analyses of these gene targets were carried out. In brief, the raw data of 105 laryngeal cancer samples were firstly extracted and then standardized by $\log _{2}($ count +1$)$. After that, the optimal cutoff was determined using survminer package in $\mathrm{R}$ language based on the expressions of candidate genes. Subsequently, the samples were divided into high- and low- expression group according to the optimal cutoff. Following this, the survival analyses of gene targets were respectively preformed with survival package in $\mathrm{R}$ language. $P<0.05$ was considered significant.

Predicting the binding mode between active compounds and key protein targets of BYQH decoction

The Protein Data Bank (PDB) offers the experimental data for determined three-dimensional (3D) biological macromolecules structure [26]. Herein, we would further explore the underlying molecular mechanism how active compounds interacted with target proteins of $\mathrm{BYQH}$ decoction. The PDB ID for the key protein was firstly acquired from PDB. Subsequently, the binding mode between key protein and corresponding active chemical ingredient was predicted by the LeDock tool. Finally, we used the Pymol software to visualize the predicted binding modes of key active ingredients to their corresponding targets.

\section{Ethics approval and consent to participate}

This study was approved by Ethics Committee of Provincial Hospital Affiliated to Shandong First Medical University and Shandong Provincial Hospital affiliated to Shandong University.

\section{Availability of data and materials}

The raw data supporting the conclusions of this manuscript will be made available by the 
authors, without undue reservation, to any qualified researcher.

\section{Highlights}

The therapeutic mechanism of $\mathrm{BYQH}$ decoction on LSCC is analyzed by network pharmacology. Sitosterol and quercetin were key active ingredients $\mathrm{BYQH}$ decoction. TP53, EGFR, NOS3 and ILIB may be therapeutic targets of LSCC.

\section{RESULTS}

\section{Active chemical compounds of BYQH decoction}

The active chemical compounds of BYQH were retrieved from TCMSP database by using five keywords of "Solanum lyratum thumb" or "Scutellaria barbata" or
"Duchesnea indica" or "Solanum nigrum" or "Actinidia chinensis Planch". Totally, 174 active ingredients were obtained: 15 in Solanum lyratum thumb, 39 in Solanum nigrum, 94 in Scutellaria barbata and 26 in Actinidia chinensis Planch, respectively. Notably, the active components of Duchesnea indica were not included in TCMSP database. Subsequently, 41 key active compounds (7 in Solanum nigrum, 28 in Scutellaria barbata and 6 in Actinidia chinensis Planch) were further screened according to the ADME parameters of $\mathrm{OB} \geq 30 \%, \mathrm{DL} \geq 0.18$ and Caco- $2 \geq-0.4$ (Table 1; Figure 1). Interestingly, sitosterol and quercetin were identified in three Chinese herbs (Solanum nigrum, Scutellaria barbata and Actinidia chinensis Planch; Table 1). In addition, beta-sitosterol was identified in Scutellaria barbata and Actinidia chinensis Planch, and cholesterol was identified in Solanum nigrum and Scutellaria barbata (Table 1).
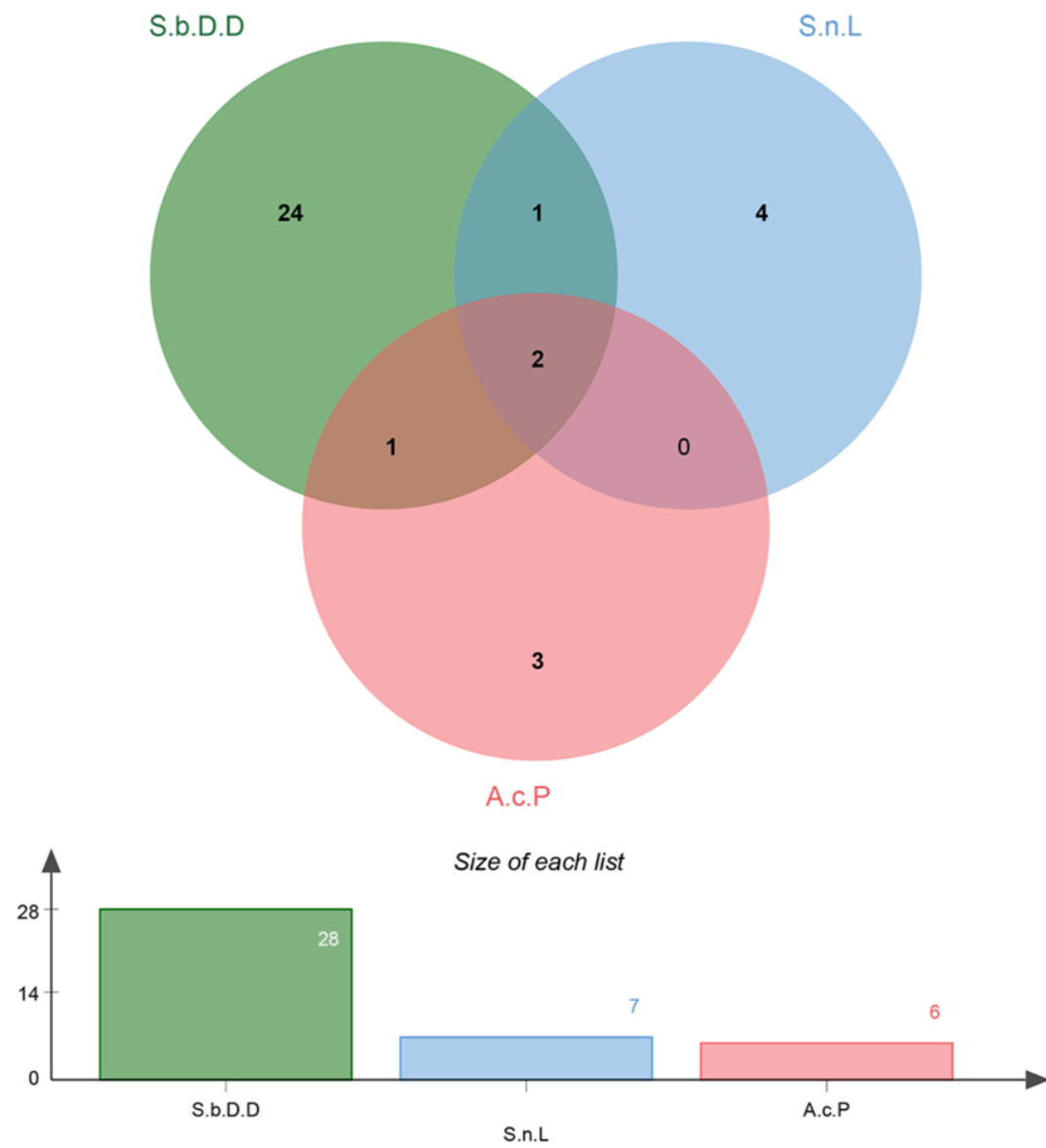

Number of elements: specific (1) or shared by 2, 3, ... lists

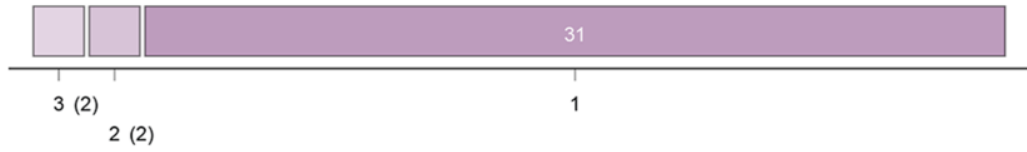

Figure 1. Venn diagrams for active ingredients of Chinese herbal medicine composition in Baiying Qinghou decoction. Abbreviations: S.b.D.D: Scutellaria barbata D. Don; S.n.L: Solanum nigrum L; A.c.P: Actinidia chinensis Planch. 
Table 1. The list of active components of Baiying Qinghou decoction.

\begin{tabular}{|c|c|c|c|c|c|c|c|c|c|c|c|}
\hline Compounds & Mol ID & Molecule Name & MW & $A \log P$ & Hdon & Hacc & OB $(\%)$ & Caco-2 & BBB & DL & HL \\
\hline S.b.D.D & MOL001040 & $\begin{array}{l}\text { (2R)-5,7-dihydroxy-2- } \\
\text { (4-hydroxyphenyl)chroman-4-one }\end{array}$ & 272.27 & 2.3 & 3 & 5 & 42.36 & 0.38 & -0.48 & 0.21 & 16.83 \\
\hline S.b.D.D & MOL012245 & 5,7,4'-trihydroxy-6-methoxyflavanone & 302.3 & 2.28 & 3 & 6 & 36.63 & 0.43 & -0.32 & 0.27 & 16.12 \\
\hline S.b.D.D & MOL012246 & 5,7,4'-trihydroxy-8-methoxyflavanone & 302.3 & 2.28 & 3 & 6 & 74.24 & 0.37 & -0.43 & 0.26 & 16.85 \\
\hline S.b.D.D & MOL012248 & $\begin{array}{l}\text { 5-hydroxy-7,8-dimethoxy-2- } \\
\text { (4-methoxyphenyl)chromone }\end{array}$ & 328.34 & 2.82 & 1 & 6 & 65.82 & 0.85 & 0.07 & 0.33 & 16.41 \\
\hline S.b.D.D & MOL012250 & $\begin{array}{l}\text { 7-hydroxy-5,8-dimethoxy-2- } \\
\text { phenyl-chromone }\end{array}$ & 298.31 & 2.84 & 1 & 5 & 43.72 & 0.96 & 0.22 & 0.25 & 16.77 \\
\hline S.b.D.D & MOL012251 & Chrysin-5-methylether & 268.28 & 2.85 & 1 & 4 & 37.27 & 0.91 & 0.16 & 0.2 & 17.24 \\
\hline S.b.D.D & MOL012252 & 9,19-cyclolanost-24-en-3-ol & 426.8 & 7.55 & 1 & 1 & 38.69 & 1.45 & 1.16 & 0.78 & 5.41 \\
\hline S.b.D.D & MOL012254 & campesterol & 400.76 & 7.63 & 1 & 1 & 37.58 & 1.34 & 0.98 & 0.71 & 4.63 \\
\hline S.b.D.D & MOL000953 & CLR & 386.73 & 7.38 & 1 & 1 & 37.87 & 1.43 & 1.13 & 0.68 & 4.52 \\
\hline S.b.D.D & MOL000358 & beta-sitosterol & 414.79 & 8.08 & 1 & 1 & 36.91 & 1.32 & 0.99 & 0.75 & 5.36 \\
\hline S.b.D.D & MOL012266 & rivularin & 344.34 & 2.55 & 2 & 7 & 37.94 & 0.65 & -0.13 & 0.37 & 16.25 \\
\hline S.b.D.D & MOL001973 & Sitosterol acetate & 456.83 & 8.46 & 0 & 2 & 40.39 & 1.39 & 1.11 & 0.85 & 6.34 \\
\hline S.b.D.D & MOL012269 & Stigmasta-5,22-dien-3-ol-acetate & 454.81 & 8.02 & 0 & 2 & 46.44 & 1.41 & 1.06 & 0.86 & 6.77 \\
\hline S.b.D.D & MOL012270 & Stigmastan-3,5,22-triene & 394.75 & 8.43 & 0 & 0 & 45.03 & 1.9 & 1.81 & 0.71 & 6.21 \\
\hline S.b.D.D & MOL000449 & Stigmasterol & 412.77 & 7.64 & 1 & 1 & 43.83 & 1.44 & 1 & 0.76 & 5.57 \\
\hline S.b.D.D & MOL000173 & wogonin & 284.28 & 2.59 & 2 & 5 & 30.68 & 0.79 & 0.04 & 0.23 & 17.75 \\
\hline S.b.D.D & MOL001735 & Dinatin & 300.28 & 2.32 & 3 & 6 & 30.97 & 0.48 & -0.49 & 0.27 & 16.44 \\
\hline S.b.D.D & MOL001755 & 24-Ethylcholest-4-en-3-one & 412.77 & 8.18 & 0 & 1 & 36.08 & 1.46 & 1.22 & 0.76 & 5.49 \\
\hline S.b.D.D & MOL002714 & baicalein & 270.25 & 2.33 & 3 & 5 & 33.52 & 0.63 & -0.05 & 0.21 & 16.25 \\
\hline S.b.D.D & MOL002719 & 6-Hydroxynaringenin & 288.27 & 2.03 & 4 & 6 & 33.23 & 0.27 & -0.27 & 0.24 & 15.67 \\
\hline S.b.D.D & MOL002915 & Salvigenin & 328.34 & 2.82 & 1 & 6 & 49.07 & 0.86 & -0.03 & 0.33 & 15.87 \\
\hline S.b.D.D & MOL000351 & Rhamnazin & 330.31 & 2.01 & 3 & 7 & 47.14 & 0.53 & -0.32 & 0.34 & 13.54 \\
\hline S.b.D.D & MOL000359 & sitosterol & 414.79 & 8.08 & 1 & 1 & 36.91 & 1.32 & 0.87 & 0.75 & 5.37 \\
\hline S.b.D.D & MOL005190 & eriodictyol & 288.27 & 2.03 & 4 & 6 & 71.79 & 0.17 & -0.54 & 0.24 & 15.81 \\
\hline S.b.D.D & MOL005869 & daucostero_qt & 414.79 & 8.08 & 1 & 1 & 36.91 & 1.32 & 0.87 & 0.75 & 5.08 \\
\hline S.b.D.D & MOL000006 & luteolin & 286.25 & 2.07 & 4 & 6 & 36.16 & 0.19 & -0.84 & 0.25 & 15.94 \\
\hline S.b.D.D & MOL008206 & Moslosooflavone & 298.31 & 2.84 & 1 & 5 & 44.09 & 1.01 & 0.54 & 0.25 & 17.02 \\
\hline S.b.D.D & MOL000098 & quercetin & 302.25 & 1.5 & 5 & 7 & 46.43 & 0.05 & -0.77 & 0.28 & 14.4 \\
\hline S.n.L & MOL002058 & 40957-99-1 & 388.45 & 2.12 & 2 & 7 & 57.2 & 0.49 & -0.29 & 0.62 & 2.04 \\
\hline S.n.L & MOL002773 & beta-carotene & 536.96 & 12 & 0 & 0 & 37.18 & 2.25 & 1.52 & 0.58 & 4.36 \\
\hline S.n.L & MOL000359 & sitosterol & 414.79 & 8.08 & 1 & 1 & 36.91 & 1.32 & 0.87 & 0.75 & 5.37 \\
\hline S.n.L & MOL000546 & diosgenin & 414.69 & 4.63 & 1 & 3 & 80.88 & 0.82 & 0.27 & 0.81 & 4.14 \\
\hline S.n.L & MOL007356 & solanocapsine & 430.75 & 3.49 & 4 & 4 & 52.94 & 0.39 & -0.22 & 0.67 & 7.86 \\
\hline S.n.L & MOL000953 & CLR & 386.73 & 7.38 & 1 & 1 & 37.87 & 1.43 & 1.13 & 0.68 & 4.52 \\
\hline S.n.L & MOL000098 & quercetin & 302.25 & 1.5 & 5 & 7 & 46.43 & 0.05 & -0.77 & 0.28 & 14.4 \\
\hline A.c.P & MOL000358 & beta-sitosterol & 414.79 & 8.08 & 1 & 1 & 36.91 & 1.32 & 0.99 & 0.75 & 5.36 \\
\hline A.c.P & MOL000359 & sitosterol & 414.79 & 8.08 & 1 & 1 & 36.91 & 1.32 & 0.87 & 0.75 & 5.37 \\
\hline A.c.P & MOL000471 & aloe-emodin & 270.25 & 1.67 & 3 & 5 & 83.38 & -0.12 & -1.07 & 0.24 & 31.49 \\
\hline A.c.P & MOL000492 & $(+)$-catechin & 290.29 & 1.92 & 5 & 6 & 54.83 & -0.03 & -0.73 & 0.24 & 0.61 \\
\hline A.c.P & MOL000073 & ent-Epicatechin & 290.29 & 1.92 & 5 & 6 & 48.96 & 0.02 & -0.64 & 0.24 & 0.63 \\
\hline A.c.P & MOL000098 & quercetin & 302.25 & 1.5 & 5 & 7 & 46.43 & 0.05 & -0.77 & 0.28 & 14.4 \\
\hline
\end{tabular}

Abbreviations: S.b.D.D: Scutellaria barbata D. Don; S.n.L: Solanum nigrum L; A.c.P: Actinidia chinensis Planch; Mol ID: molecule ID; MW: molecular weight; AlogP: lipid-water partition coefficient; Hdon/Hacc: the number of hydrogen-bonding donor or acceptor; OB: oral bioavailability; BBB: blood brain barrier; Caco-2: Caco-2 permeability; DL: drug-likeness; HL: half-life.

\section{Functional enrichment analysis of targets of the active Ingredients of BYQH decoction}

Totally, 137 gene targets of the active ingredients of $\mathrm{BYQH}$ decoction were predicted according to the methods mentioned above (Supplementary Table 1). Afterwards, the functional enrichment analyses of these genes were conducted to investigate their potential biological roles in LSCC treatment. The results showed that they were enriched in 1444 GO-BP terms, 114 GO$\mathrm{CC}$ terms and $203 \mathrm{GO}-\mathrm{MF}$ terms. Figure 2 showed top 10 significantly enriched $\mathrm{GO}$ terms in $\mathrm{MF}, \mathrm{CC}$, and $\mathrm{BP}$. At the cellular level, the gene targets were dramatically enriched in cellular response to chemical stimulus 
(involved with TP53, EGFR, NOS3 and ILIB et al.), response to drug and response to chemical (involved with TP53, EGFR, NOS3 and IL1B et al.). The membrane raft, plasma membrane region and plasma membrane raft were the three GO-CC terms enriched by gene targets. For GO-MF category, these genes were significantly involved in protein binding, enzyme biding and molecular transducer activity. In addition, the KEGG enrichment analysis revealed that the target genes were enriched in 172 pathways. Moreover, we found they were primarily correlated with several cancer-related pathways, such as PI3K-Akt signaling pathway (involved with BCL2, EGFR, NOS3 and TP53 et al.), estrogen signaling pathway (involved with BCL2, EGFR, MMP2, NOS3 et al.) and HIF-1 signaling pathway (involved with EGF, EGFR, IL6 and NOS3 et al.). These findings suggested that BYQH decoction may have essential effect on the treatment of LSCC.

\section{Target PPI network analysis}

The potential interactions among target proteins of $\mathrm{BYQH}$ decoction was constructed and visualized by

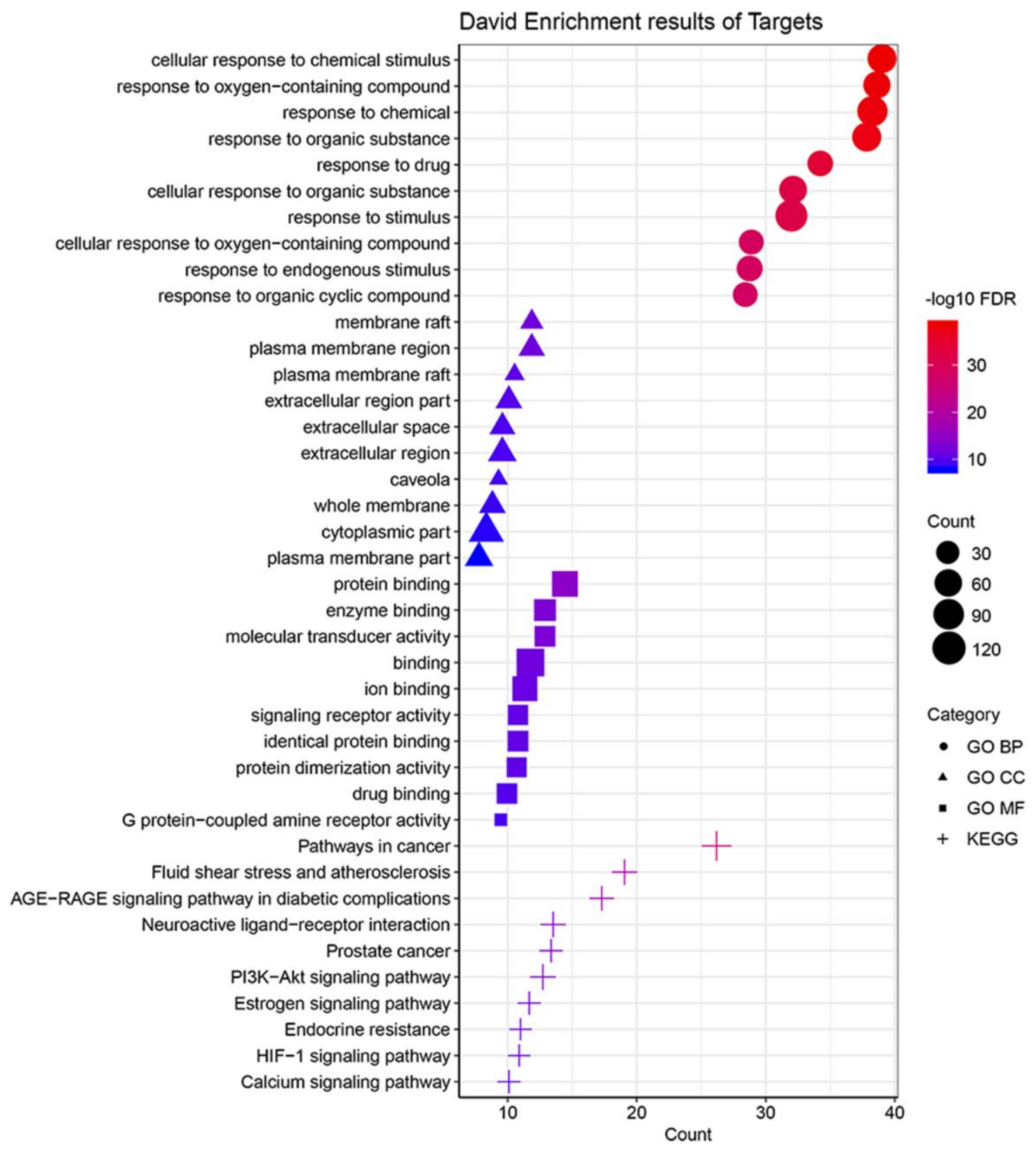

Figure 2. Functional analyses of target genes of Baiying Qinghou decoction. The top 10 significantly enriched GO-BP/MF/CC terms and KEGG pathways were displayed. Abbreviations: GO: Gene Ontology; KEGG: Kyoto Encyclopedia of Genes and Genomes; BP: biological process; CC: cellular component; MF: molecular function. 
STRING database. As shown in Figure 3, there were 128 protein nodes and 1282 edges in PPI network. The protein nodes with higher degree may have closer biological connection with other nodes. Herein, the top 15 nodes were regarded as hub genes and listed in Table 2, including IL6 (interleukin-6 degree $=67$ ), $V E G F A$ (vascular endothelial growth factor A; degree = 63), TP53 $($ degree $=61), J U N($ degree $=58), E G F$ $($ degree $=57), M A P K 1($ degree $=54), E G F R($ degree $=$ $53), P T G S 2($ degree $=52)$, ESR1 $($ degree $=51), C A T$ $($ degree $=49)$, NOS3 $($ degree $=48), I L 1 B($ degree $=$ 47), HSP90AA1 $($ degree $=44), C C L 2($ degree $=44)$, and $A R($ degree $=43)$.

\section{Cross-validation of target proteins}

To further narrow the range of potential target genes of $\mathrm{BYQH}$ decoction, the candidate target genes were cross-validated. The genes related to LSCC were respectively acquired from Phenopedia and DisGeNET database, which provided information on gene-disease interactions. Then, the intersecting target genes were obtained between predicted genes and gene targets of $\mathrm{BYQH}$ decoction. Finally, a total of 10 intersectionassociated genes were extracted, including $P T G S 2$, NOS3, BCL2, ADH1C, TP53, MPO, EGFR, GSTP1, $I L I B$ and GSTMI (Figure 4). Among them, five genes (TP53, EGFR, PTGS2, NOS3 and ILIB) served as the hub genes in PPI network. Therefore, these genes were considered to be key targets of $\mathrm{BYQH}$ decoction against LSCC.

\section{Survival analysis}

To explore the underlying impacts of 10 key gene targets on the clinical prognosis of LSCC, we conducted

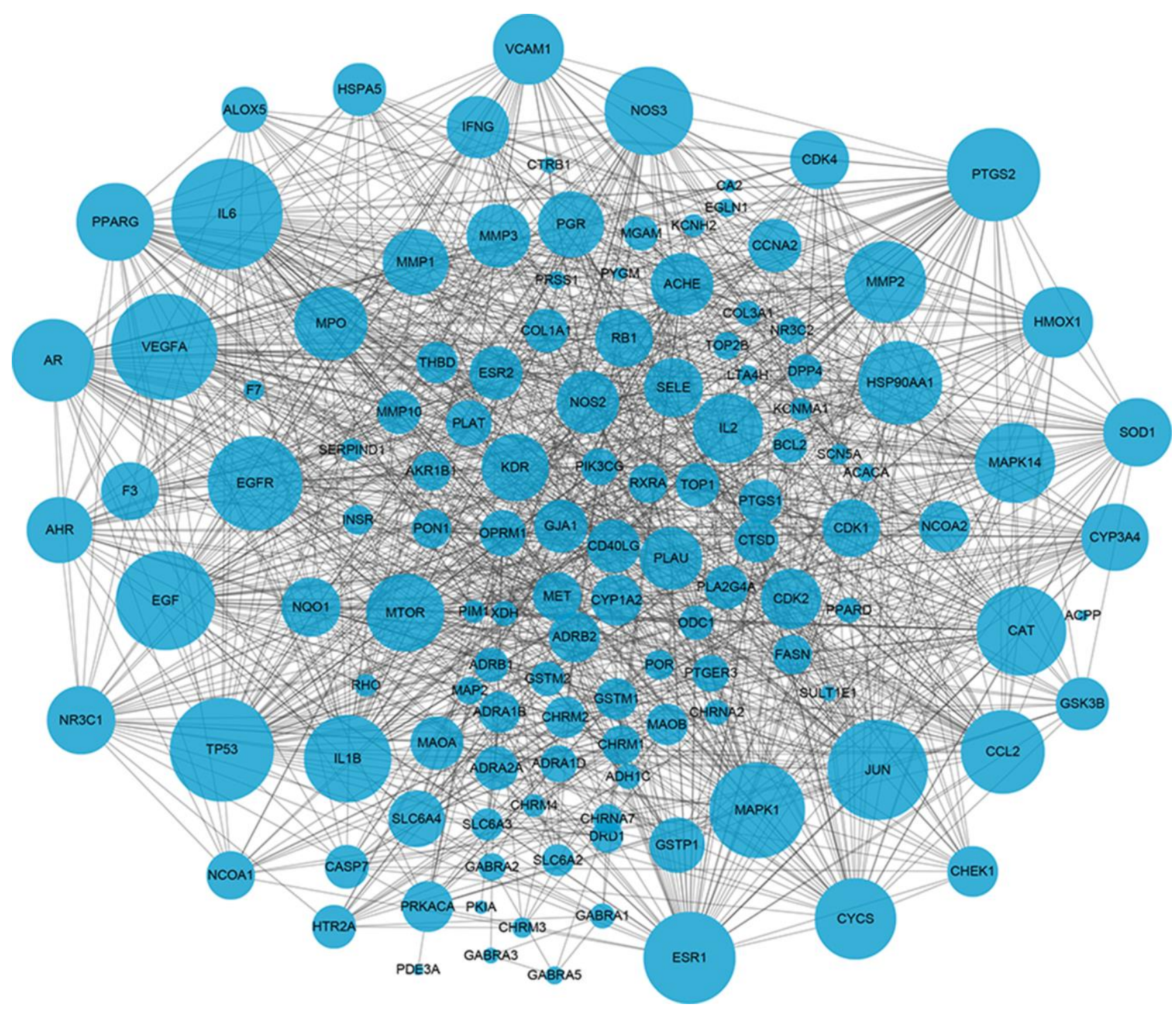

Figure 3. The protein-protein interaction (PPI) network of key target genes of Baiying Qinghou decoction. Dots represent target proteins/genes and the lines represents interactions among proteins/targets. The larger dot size shows the higher degree. 
Table 2. The top 15 hub proteins in protein-protein interaction network.

\begin{tabular}{lccc}
\hline Name & Degree & Betweenness centrality & Closeness centrality \\
\hline IL6 & 67 & 0.080 & 0.658 \\
VEGFA & 63 & 0.050 & 0.638 \\
TP53 & 61 & 0.031 & 0.608 \\
JUN & 58 & 0.043 & 0.626 \\
EGF & 57 & 0.058 & 0.623 \\
MAPK1 & 0.022 & 0.593 \\
EGFR & 54 & 0.035 & 0.608 \\
PTGS2 & 53 & 0.030 & 0.599 \\
ESR1 & 52 & 0.031 & 0.585 \\
CAT & 51 & 0.058 & 0.591 \\
NOS3 & 49 & 0.063 & 0.599 \\
IL1B & 48 & 0.021 & 0.593 \\
HSP90AA1 & 0.023 & 0.561 \\
CCL2 & 47 & 0.013 & 0.559 \\
AR & 44 & 0.029 & 0.555 \\
\hline
\end{tabular}

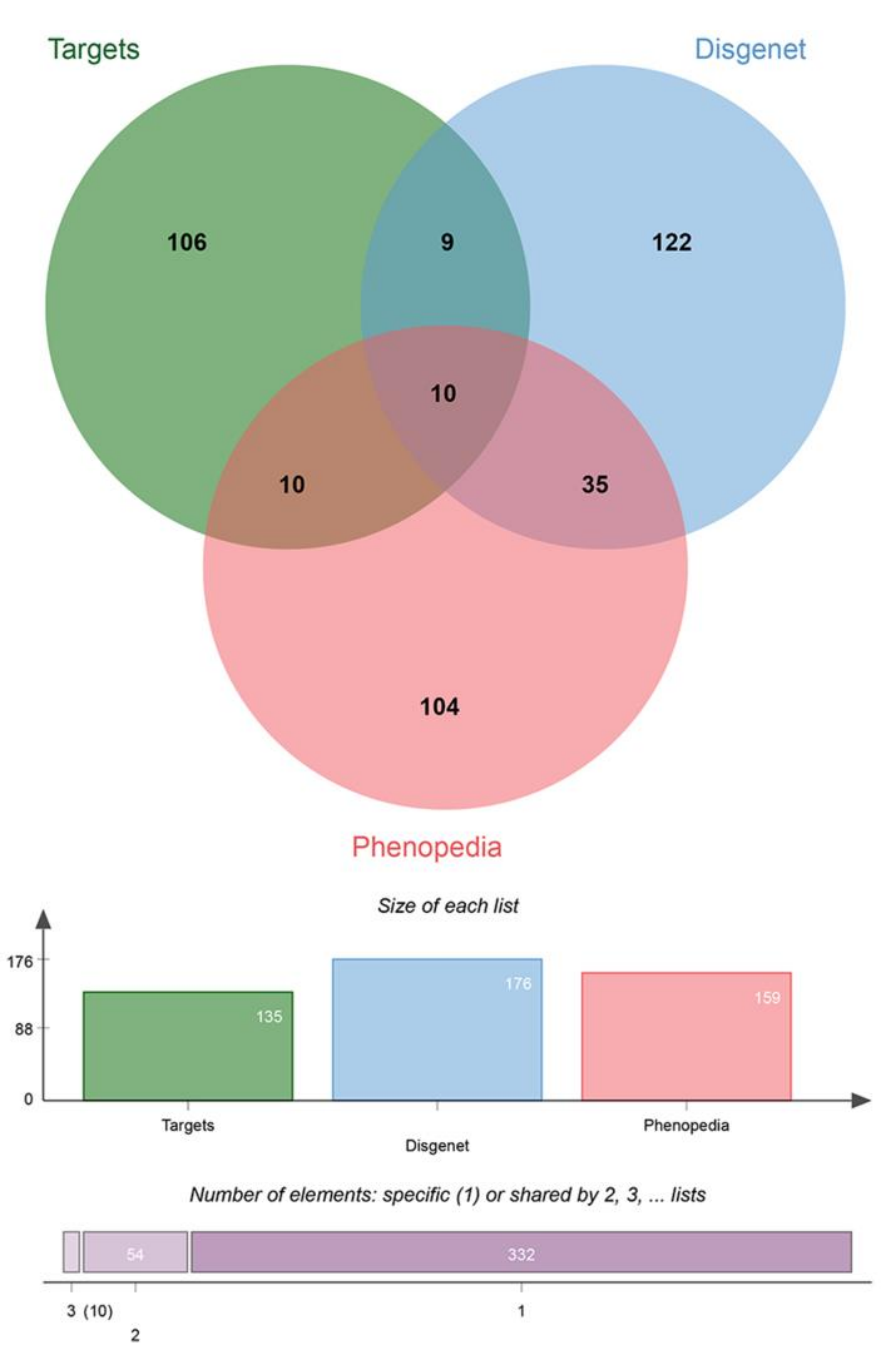

Figure 4. Venn diagrams for cross-validation gene targets by Phenopedia and DisGeNET databases. The intersecting genes were extracted between gene targets of Baiying Qinghou decoction and genes related to laryngeal cancer in Phenopedia and DisGeNET databases. 
the survival analyses using TCGA data of 105 HNSCC patients. The expression patterns of these genes were firstly determined among tissue samples of 105 HNSCC patients. Then, we calculated the optimal cutoff value of each gene to stratify all patients into high- and low-expression groups. Our results showed that the optimal cutoff value was 2.58 for $A D H 1 C, 7.03$ for $B C L 2,15.13$ for $E G F R, 13.45$ for $G S T M 1,16.06$ for $G S T P 1,10.53$ for $I L 1 B, 5.29$ for $M P O, 8.5$ for NOS3, 9.36 for PTGS2, and 10.95 for TP53 (Figure 5 and Supplementary Figure 1). Survival analysis revealed that seven genes $(A D H I C$,
EGFR, GSTM1, GSTP1, IL1B, NOS3 and TP53) were significantly associated with the prognosis of HNSCC patients $(P<0.05$; Figure 5). Moreover, HNSCC patients with a high expression level of $A D H 1 C$ had a better prognosis $(P=0.012$; Figure 5). However, the high expression levels of the remaining six genes were closely related to the unfavorable prognosis of HNSCC patients (EGFR: $P=0.014$; GSTM1: $P=0.004$; GSTP1: $P=0.034 ; I L 1 B: P=$ 0.03; NOS3: $P=0.039$ and TP53: $P=0.02$; Figure 5). Notably, TP53, EGFR, NOS3 and IL1B also acted as hub genes in PPI network.
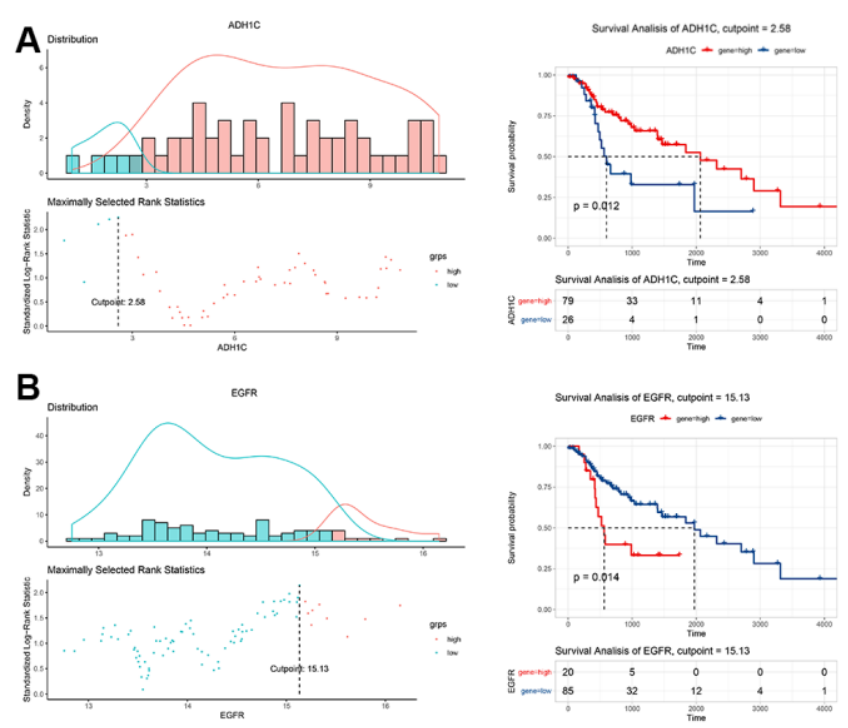

C
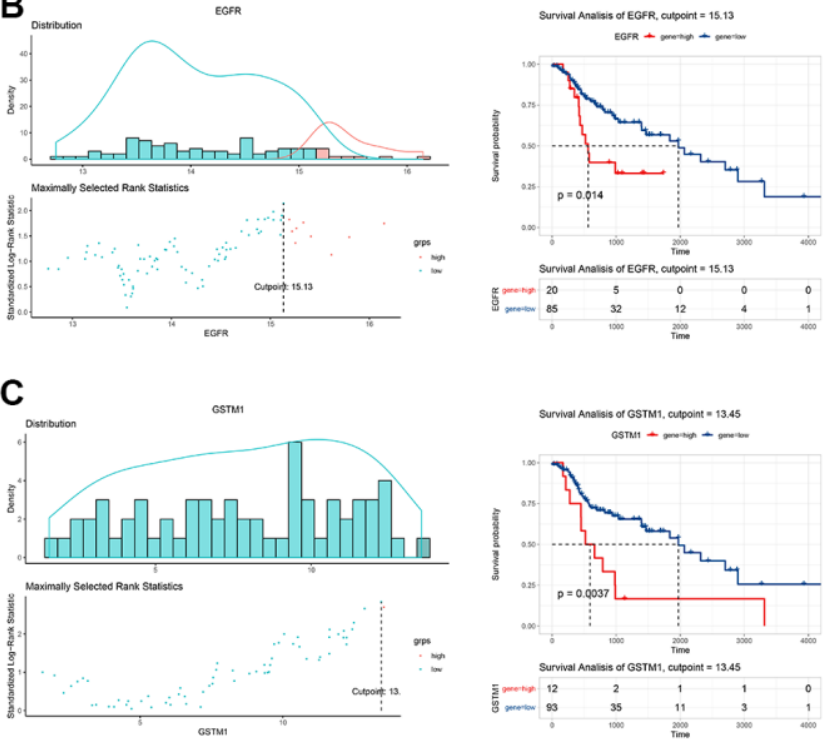

$\mathbf{F}$

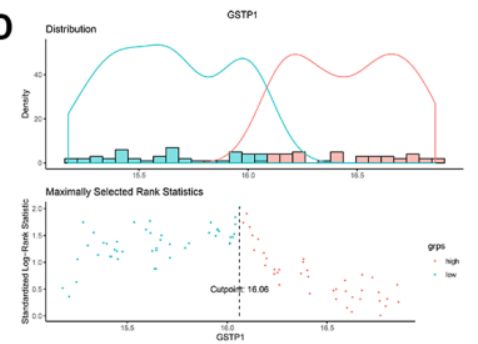

E
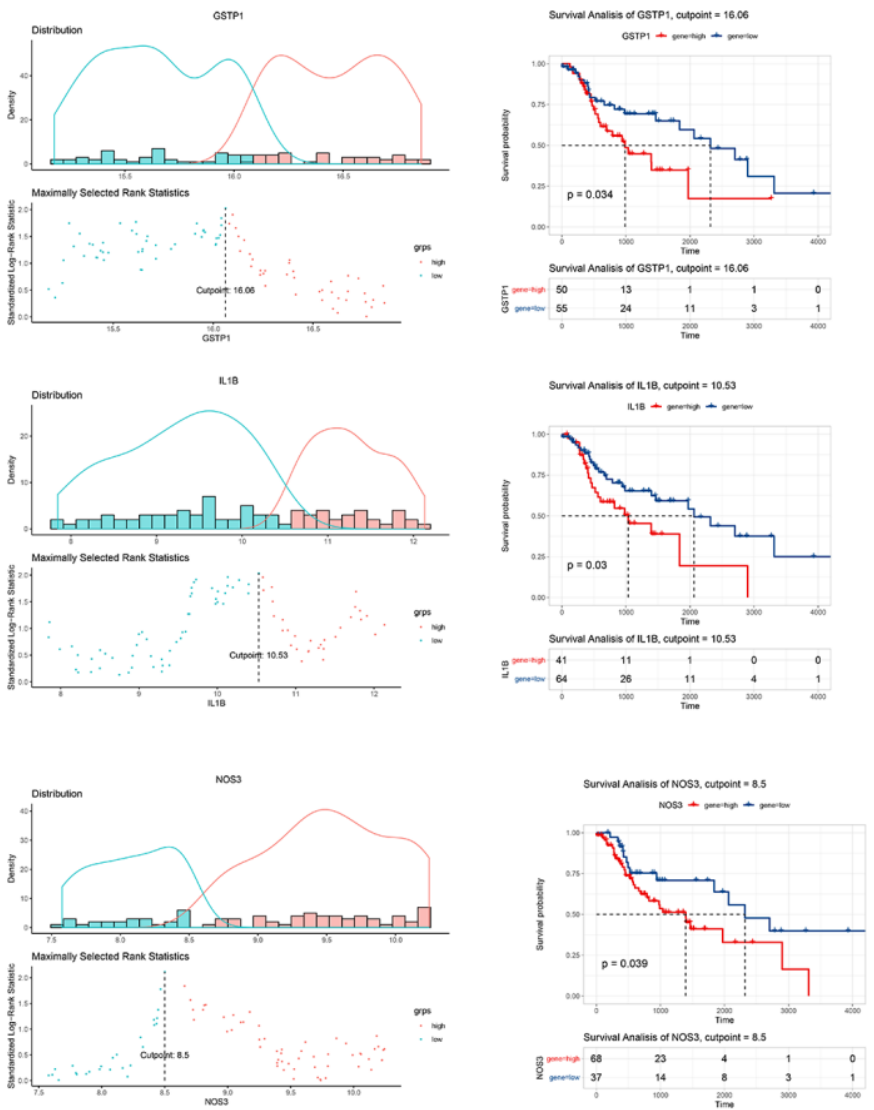
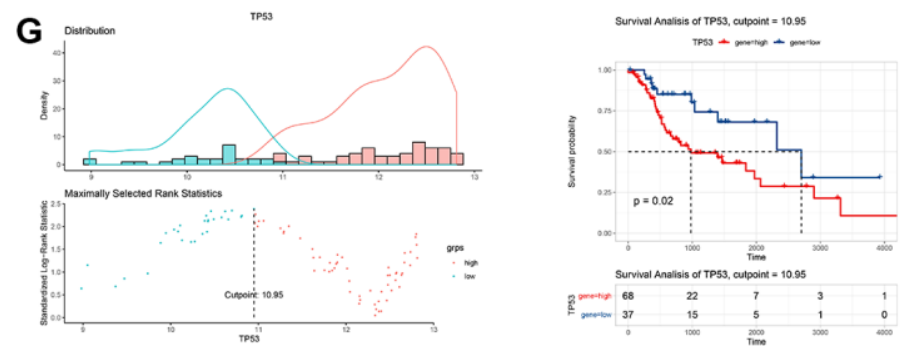

Figure 5. Survival analysis of key target genes of Baiying Qinghou decoction using a TCGA dataset. The optimal cutoff value of each gene was calculated to stratify all patients into high- and low-expression groups (the left of the $\mathbf{A}-\mathbf{G}$ ). Seven genes (ADH1C, EGFR, GSTM1, GSTP1, IL1B, NOS3 and TP53) were significantly associated with the prognosis of HNSCC patients (the right of the $\mathbf{A}-\mathbf{G})$. The high expression level of $A D H 1 C(\mathbf{A})$ had a better prognosis of HNSCC patients $(P=0.012)$. However, the high expression levels of EGFR (B), GSTM1 (C), GSTP1 (D), IL1B (E), NOS3 (F) and TP53 (G) showed the poor prognosis of HNSCC patients. Abbreviations: HNSCC: head and neck squamous cell carcinoma; TCGA: The Cancer Genome Atlas. 


\section{Prediction of the binding mode between key bioactive compounds and proteins}

The binding characteristics of key active ingredients of BYQH decoction and four key protein targets (TP53, EGFR, NOS3 and ILIB) were investigated. Herein, we focused on analyzing the binding modes between two overlapped active compounds (sitosterol and quercetin) among three Chinese herbs and four target proteins. Our analysis indicated that the corresponding protein targets of sitosterol were PGR, NCOA2, NR3C2, which were not targets studied. For quercetin, 75 target proteins were obtained, including four key protein targets. Subsequently, the chemical structure formula of quercetin was acquired from TSMCP database, and four target proteins were also searched from PDB database, including TP53 (PDB ID: 3ZME), EGFR (PDB ID: 1XKK), NOS3 (PDB ID: 6PP1) and IL1B (PDB ID: 5R86). Finally, the molecular docking was carried out using LeDock tool. Notably, a closer binding between proteins and small biological molecules indicated more energy released and a lower $\Delta \mathrm{G}$ value. Figure 6 depicted the optimal binding modes of quercetin and its four target proteins.

\section{DISCUSSION}

TCM is an accepted medical practice and has been used for the treatment of complicated diseases such as cancers over past few decades in China [27, 28]. BYQH decoction, a TCM prescription, has been clinically proven to be effective as adjuvant treatment against LSCC. In this study, we performed a network pharmacological analysis to explore pharmacodynamic effects and therapeutic mechanism of BYQH decoction for LSCC. We identified 41 key active ingredients of $\mathrm{BYQH}$ decoction. Of these, sitosterol and quercetin were intersected among three Chinese herbs of BYQH decoction. Moreover, these crucial components were corresponded to 137 target proteins. Top 15 genes (IL6, VEGFA, TP53, JUN, EGF, MAPK1, EGFR, PTGS2, ESR1, CAT, NOS3, IL1B, HSP9OAA1, CCL2 and AR) were considered as hub nodes in PPI network. Among them, five proteins (TP53, EGFR, PTGS2, NOS3 and $I L 1 B$ ) were cross-validated. Additionally, survival analysis showed the expressions of ADH1C, EGFR, GSTM1, GSTP1, IL1B, NOS3 and TP53 were markedly correlated with the prognosis of HNSCC patients. Finally, the binding modes of quercetin and four target proteins (TP53, EGFR, NOS3 and IL1B) were constructed.

Quercetin (3,3', 4',5,7-pentahydroxyflavone), a common flavonol, is widely distributed in plant species, such as vegetables and grains. Our results showed that quercetin was a key active chemical compound of BYQH decoction. Extensive evidence suggests that quercetin exerts diverse biological functions, such as antioxidant, anti-inflammatory, anti-bacterial, antiviral and anticarcinogenic properties [29-31]. Numerous studies have evaluated the anticarcinogenic effects of quercetin and indicated that quercetin was involved in regulating several cancer-related pathways, such PI3K/Akt/ signaling pathways and MAPK/ERK1/2 pathways [32, 33]. Sharma et al. report that quercetin induced human laryngeal $\mathrm{HeP} 2$ cells death and synergistically enhanced the antiproliferative ability of cisplatin in these cells [34]. Numerous researchers demonstrate that quercetin $(50 \mu \mathrm{M})$ can significantly increase photodynamic therapy-induced cytotoxicity via reducing the cell viability of human larynx carcinoma cells (HEp-2) [35]. In addition, the apoptotic events are increased stronger in HEp-2 cells with the combination of quercetin than the single drug treatment [36]. These evidences reveals that quercetin may be a promising therapeutic molecule for LSCC treatment.

TP53, EGFR, NOS3 and ILIB were key hub genes in PPI network of target proteins of BYQH decoction and cross-validated in two databases (Phenopedia and DisGeNET). More notably, these four proteins were also target proteins of quercetin. p53 protein encoded by TP53 gene functions as a tumor-suppressive factor by regulating multiple cellular processes such as cell-cycle progression and apoptosis [37]. Overwhelming evidence suggests several mutations in TP53 can influence the progression of HNSCC and clinical treatment response $[38,39]$. Clemente-Soto $\mathrm{AF}$ et al. point out that quercetin can induce G2 phase cell cycle arrest and apoptosis in human cervical cancer cells, accompanied by upregulating p53 level [40]. Our molecular docking analysis suggested that quercetin can strongly bind with TP53. EGFR is frequently reported to be associated with HNSCC [41]. Chan et al. indicate that quercetin may suppress cell migration and invasion of HNSCC cells overexpressing EGFR by down-regulating the expression of $M M P-2$ and $M M P-9$ [42]. Similarly, Chung et al. indicate that there is a high frequency of EGFR copy number in HNSCC, which acts as a poor predictor for the prognosis of HNSCC patients [43]. $I L I B$ is an inflammatory cytokine gene and acts as a therapeutic target for the treatment of head and neck cancer $[44,45]$. NOS3 is located on chromosome 7 (7q36) and regulates at transcriptional and posttranscriptional levels [46]. Previous studies identified numerous polymorphic sites of NOS3 such as single nucleotide polymorphism and insertion or deletion [47, 48]. Moreover, the NOS3 polymorphisms play crucial roles in the molecular mechanism of cancers and clinical survivals of patients undergoing cancers, including laryngeal cancer [49-51]. Guo et al. recently 
report that quercetin has a binding interaction with NOS3, which was consistent with our finding [52]. Besides, we also found the elevated level of NOS3 represented an unfavorable prognosis.
Besides, in this study, GO enrichment analysis showed that the four genes of interest (TP53, EGFR, NOS3 and $I L 1 B$ ) were significantly enriched in cellular response to chemical stimulus, response to chemical, response to

A
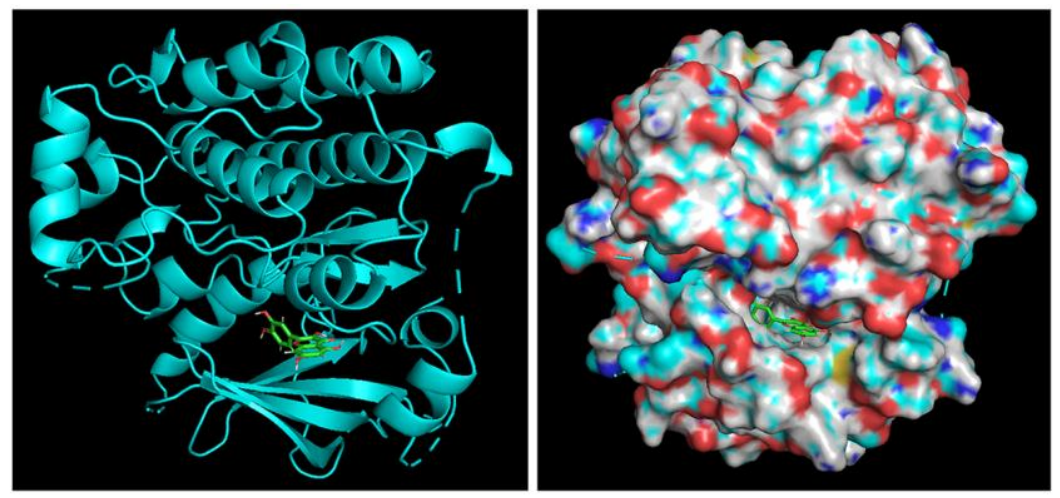

B

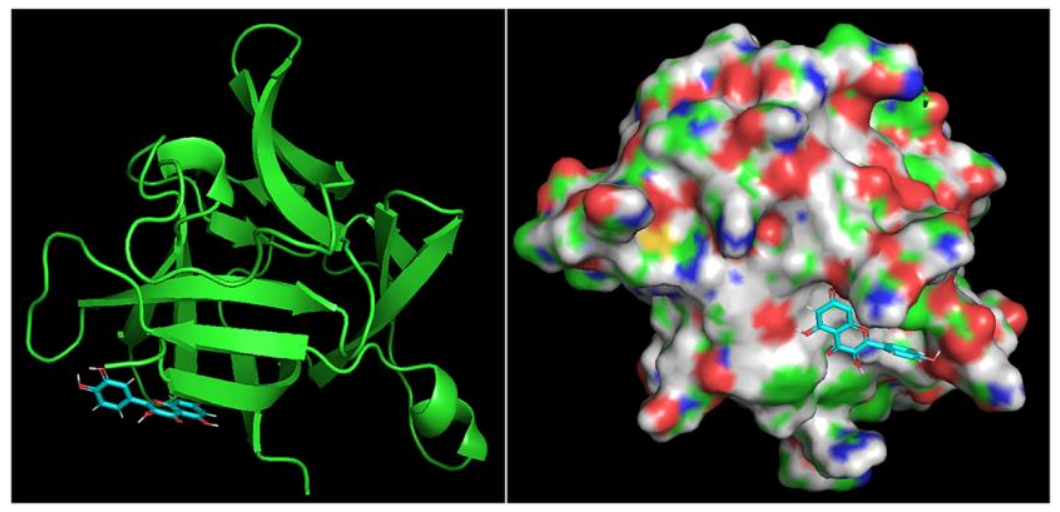

C

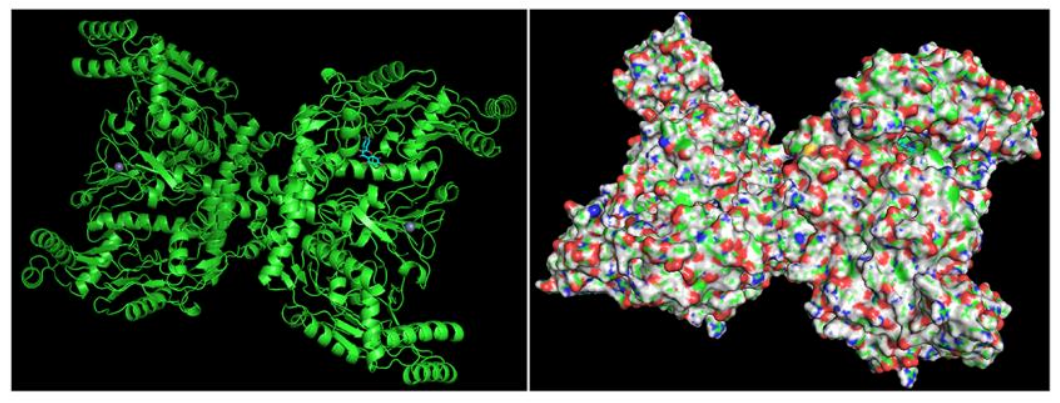

D
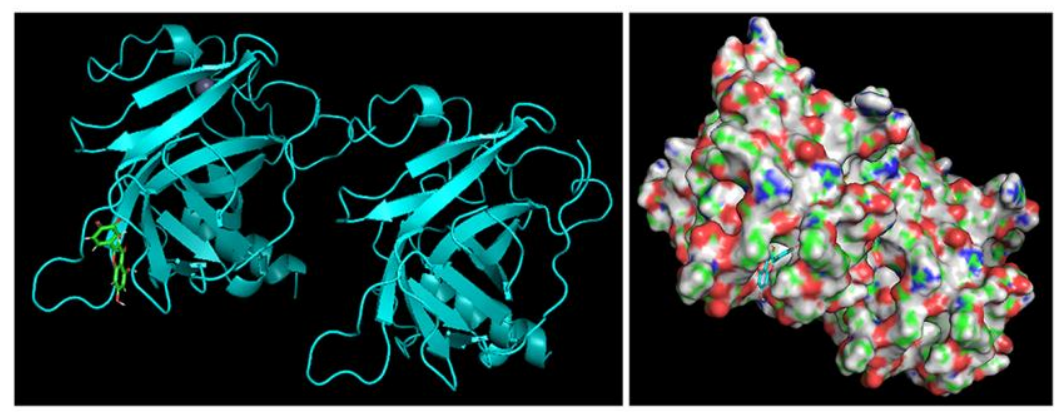

Figure 6. The binding modes. (A) The binding modes of quercetin and $E G F R$. The optimal binding modes of quercetin and $E G F R(\triangle G=$ $-6.87 \mathrm{kcal} / \mathrm{mol})$. Left: two-dimensional image; Right: three-dimensional image. (B) The binding modes of quercetin and IL1B. The optimal binding modes of quercetin and $I L I B(\Delta G=-4.84 \mathrm{kcal} / \mathrm{mol})$. Left: two-dimensional image; Right: three-dimensional image. (C) The binding modes of quercetin and NOS3. The optimal binding modes of quercetin and NOS3 ( $\triangle \mathrm{G}=-7.12 \mathrm{kcal} / \mathrm{mol})$. Left: two-dimensional image; Right: three-dimensional image. (D) The binding modes of quercetin and TP53. The optimal binding modes of quercetin and TP53 $(\triangle \mathrm{G}=$ $-6.15 \mathrm{kcal} / \mathrm{mol})$. Left: two-dimensional image; Right: three-dimensional image. 
drug related biological processes. TP53 is a short-lived protein that plays a central role in mediating cellular response to stressful and genotoxic stimuli, such as anticancer drugs exposure [53]. EGFR has been proposed to be the prognostic marker for HNSCC that closely related with radiation sensitivity, tumor size and recurrence [54]. Additionally, our survival data showed that the high expression of TP53, EGFR, NOS3 and $I L 1 B$ in HNSCC patients exhibited a poor prognosis, which was consistent with the previous reports mentioned above. Thus, we speculated that the quercetin might reduce drug resistance of HNSCC by targeting TP53, EGFR, NOS3 and ILIB.

Furthermore, PI3K-AKT signaling is considered to be a classical pathway related with various cancers $[55,56]$. The descending activation of PI3K-AKT signaling is closely associated with radiosensitivity enhancement of LSCC patients [57]. The reduced protein expressions of PI3K and AKT are accompanied by suppressed LSCC tumor growth [58]. In this study, PI3K-AKT signaling was identified to a significant pathway involved with TP53, EGFR, NOS3. Our findings supported the significant role of PI3K-AKT signaling pathway in LSCC and proposed the target role of the key proteins identified in this study.

Although our study identified several key components and target proteins of BYQH decoction, relevant experimental assays are needed to validate our findings. Although were considered as the prognostic indicators for patients with LSCC, The expression patterns of the four candidate prognostic indicators in LSCC have not been investigated in clinical samples. Moreover, the relationships of these prognostic genes and some clinical parameters are also not analyzed. Additionally, many chemical compounds are possibly not identified because the limited data is available in public databases, which may lead to some false positive results.

\section{CONCLUSIONS}

Network pharmacology analysis was carried out to elucidate the therapeutic role of $\mathrm{BYQH}$ decoction on LSCC. Quercetin was predicted to be the active compounds of BYQH decoction by targeting TP53, $E G F R, N O S 3$ and $I L 1 B$ involved in drug resistance and PI3K-AKT signaling pathway. Moreover, the four genes of TP53, EGFR, NOS3 and IL1B exerted promising prognostic potential for LSCC. Our results offered an important clue for uncovering the underlying mechanism of $\mathrm{BYQH}$ decoction in the treatment of LSCC. However, more experimental evidences about the effects of quercetin on LSCC in vivo and in vitro by targeting TP53, EGFR, NOS3 and ILIB are warranted in the near future.

\section{Abbreviations}

BYQH: Baiying Qinghou; LSCC: laryngeal squamous cell carcinoma; PPI: protein-protein interaction; HNC: Head and neck cancer; HNSCC: Head and neck squamous cell carcinoma; TCM: Traditional Chinese medicines; GO: Gene Ontology; OB: oral bioavailability, blood brain barrier; Caco-2: Caco-2 permeability; DL: drug-likeness; HL: half-life; BP: biological process; CC: cellular component; MF: molecular function.

\section{AUTHOR CONTRIBUTIONS}

Aiai Lv, Xuanchen Zhou and Kun Gao carried out the Conception and design of the research, Kun Gao and Xianwei Gong participated in the Acquisition of data. Kun Gao and Yanan Zhu carried out the Analysis and interpretation of data. Kun Gao and Hui Wang participated in the design of the study and performed the statistical analysis. Zhiyong Yue participated in Obtaining funding. Aiai Lv, Xuanchen Zhou, Kun Gao and Aiai Lv conceived of the study, and participated in its design and coordination and helped to draft the manuscript and revision of manuscript for important intellectual content. All authors read and approved the final manuscript.

\section{CONFLICTS OF INTEREST}

The authors declare no conflicts of interest related to this study.

\section{FUNDING}

This work was supported by 2018 the Key R\&D Program of Shandong Province (Program No. 2018GSF118192).

\section{REFERENCES}

1. Chow LQM. Head and Neck Cancer. N Engl J Med. 2020; 382:60-72. https://doi.org/10.1056/NEJMra1715715 PMID:31893516

2. Marur S, Forastiere AA. Head and Neck Squamous Cell Carcinoma: Update on Epidemiology, Diagnosis, and Treatment. Mayo Clin Proc. 2016; 91:386-96. https://doi.org/10.1016/i.mayocp.2015.12.017 PMID:26944243

3. Pedregal-Mallo D, Hermida-Prado F, Granda-Díaz R, Montoro-Jiménez I, Allonca E, Pozo-Agundo E, Álvarez-Fernández M, Álvarez-Marcos C, GarcíaPedrero JM, Rodrigo JP. Prognostic Significance of the Pluripotency Factors NANOG, SOX2, and OCT4 in 
Head and Neck Squamous Cell Carcinomas. Cancers (Basel). 2020; 12:1794.

https://doi.org/10.3390/cancers12071794

PMID:32635524

4. Cossu AM, Mosca L, Zappavigna S, Misso G, Bocchetti M, De Micco F, Quagliuolo L, Porcelli M, Caraglia M, Boccellino $M$. Long Non-coding RNAs as Important Biomarkers in Laryngeal Cancer and Other Head and Neck Tumours. Int J Mol Sci. 2019; 20:3444.

https://doi.org/10.3390/ijms20143444 PMID:31336999

5. Li Y, Wang K, Yin S, Zheng H, Min D. Xanthohumol inhibits proliferation of laryngeal squamous cell carcinoma. Oncol Lett. 2016; 12:5289-94.

https://doi.org/10.3892/ol.2016.5313 PMID:28105237

6. So TH, Chan SK, Lee VH, Chen BZ, Kong FM, Lao LX. Chinese Medicine in Cancer Treatment - How is it Practised in the East and the West? Clin Oncol (R Coll Radiol). 2019; 31:578-88.

https://doi.org/10.1016/i.clon.2019.05.016 PMID:31178347

7. Li J, Wu Y, Wang D, Zou L, Fu C, Zhang J, Leung GP. Oridonin synergistically enhances the anti-tumor efficacy of doxorubicin against aggressive breast cancer via pro-apoptotic and anti-angiogenic effects. Pharmacol Res. 2019; 146:104313.

https://doi.org/10.1016/i.phrs.2019.104313 PMID:31202781

8. Guo R, Luo X, Liu J, Liu L, Wang X, Lu H. Omics strategies decipher therapeutic discoveries of traditional Chinese medicine against different diseases at multiple layers molecular-level. Pharmacol Res. 2020; 152:104627. https://doi.org/10.1016/i.phrs.2020.104627 PMID:31904505

9. Gerber B, Scholz C, Reimer T, Briese V, Janni W. Complementary and alternative therapeutic approaches in patients with early breast cancer: a systematic review. Breast Cancer Res Treat. 2006; 95:199-209.

https://doi.org/10.1007/s10549-005-9005-y PMID:16254687

10. Zhong $Y$, Lee $K$, Deng $Y$, Ma $Y$, Chen $Y$, Li X, Wei C, Yang S, Wang T, Wong NJ, Muwonge AN, Azeloglu EU, Zhang $W$, et al. Arctigenin attenuates diabetic kidney disease through the activation of PP2A in podocytes. Nat Commun. 2019; 10:4523. https://doi.org/10.1038/s41467-019-12433-w PMID:31586053

11. Tan X, Luo Q, Zhou S, Huang W, Feng X, Chen W, Yang C, Li Y. Erchen Plus Huiyanzhuyu Decoction Inhibits the Growth of Laryngeal Carcinoma in a Mouse Model of Phlegm-Coagulation-Blood-Stasis Syndrome via the STAT3/Cyclin D1 Pathway. Evid Based Complement Alternat Med. 2020; 2020:2803496.

https://doi.org/10.1155/2020/2803496

PMID:32382281

12. Hopkins AL. Network pharmacology. Nat Biotechnol. 2007; 25:1110-1. https://doi.org/10.1038/nbt1007-1110 PMID:17921993

13. Fang J, Liu C, Wang $Q$, Lin $P$, Cheng $F$. In silico polypharmacology of natural products. Brief Bioinform. 2018; 19:1153-71.

https://doi.org/10.1093/bib/bbx045 PMID:28460068

14. Gao L, Wang XD, Niu YY, Duan DD, Yang $X$, Hao J, Zhu CH, Chen D, Wang KX, Qin XM, Wu XZ. Molecular targets of Chinese herbs: a clinical study of hepatoma based on network pharmacology. Sci Rep. 2016; 6:24944.

https://doi.org/10.1038/srep24944 PMID:27143508

15. Huang J, Guo W, Cheung F, Tan HY, Wang N, Feng Y. Integrating Network Pharmacology and Experimental Models to Investigate the Efficacy of Coptidis and Scutellaria Containing Huanglian Jiedu Decoction on Hepatocellular Carcinoma. Am J Chin Med. 2020; 48:161-82.

https://doi.org/10.1142/S0192415X20500093 PMID:31964157

16. Ru J, Li P, Wang J, Zhou W, Li B, Huang C, Li P, Guo Z, Tao W, Yang Y, Xu X, Li Y, Wang Y, Yang L. TCMSP: a database of systems pharmacology for drug discovery from herbal medicines. J Cheminform. 2014; 6:13. https://doi.org/10.1186/1758-2946-6-13 PMID:24735618

17. Dong J, Wang NN, Yao ZJ, Zhang L, Cheng Y, Ouyang D, Lu AP, Cao DS. ADMETlab: a platform for systematic ADMET evaluation based on a comprehensively collected ADMET database. J Cheminform. 2018; 10:29.

https://doi.org/10.1186/s13321-018-0283-x PMID:29943074

18. Ertl P, Rohde B, Selzer P. Fast calculation of molecular polar surface area as a sum of fragment-based contributions and its application to the prediction of drug transport properties. J Med Chem. 2000; 43:3714-7.

https://doi.org/10.1021/im000942e PMID: 11020286

19. Huang J, Cheung F, Tan HY, Hong M, Wang N, Yang J, Feng $Y$, Zheng $Q$. Identification of the active 
compounds and significant pathways of yinchenhao decoction based on network pharmacology. Mol Med Rep. 2017; 16:4583-92.

https://doi.org/10.3892/mmr.2017.7149

PMID:28791364

20. Wishart DS, Feunang YD, Guo AC, Lo EJ, Marcu A, Grant JR, Sajed T, Johnson D, Li C, Sayeeda Z, Assempour N, lynkkaran I, Liu Y, et al. DrugBank 5.0: a major update to the DrugBank database for 2018. Nucleic Acids Res. 2018; 46:D1074-82. https://doi.org/10.1093/nar/gkx1037 PMID:29126136

21. von Mering $C$, Jensen $L$, Snel B, Hooper SD, Krupp M, Foglierini $M$, Jouffre $N$, Huynen MA, Bork P. STRING: known and predicted protein-protein associations, integrated and transferred across organisms. Nucleic Acids Res. 2005; 33:D433-7. https://doi.org/10.1093/nar/gki005 PMID:15608232

22. Piñero J, Bravo À, Queralt-Rosinach N, GutiérrezSacristán A, Deu-Pons J, Centeno E, García-García J, Sanz F, Furlong LI. DisGeNET: a comprehensive platform integrating information on human diseaseassociated genes and variants. Nucleic Acids Res. 2017; 45:D833-9.

https://doi.org/10.1093/nar/gkw943

PMID:27924018

23. Piñero J, Queralt-Rosinach N, Bravo À, Deu-Pons J, Bauer-Mehren A, Baron M, Sanz F, Furlong LI. DisGeNET: a discovery platform for the dynamical exploration of human diseases and their genes. Database (Oxford). 2015; 2015:bav028.

https://doi.org/10.1093/database/bav028 PMID:25877637

24. Yu W, Clyne M, Khoury MJ, Gwinn M. Phenopedia and Genopedia: disease-centered and gene-centered views of the evolving knowledge of human genetic associations. Bioinformatics. 2010; 26:145-6. https://doi.org/10.1093/bioinformatics/btp618 PMID:19864262

25. Bardou P, Mariette J, Escudié F, Djemiel C, Klopp C. jvenn: an interactive Venn diagram viewer. BMC Bioinformatics. 2014; 15:293.

https://doi.org/10.1186/1471-2105-15-293 PMID:25176396

26. Berman HM, Westbrook J, Feng Z, Gilliland G, Bhat TN, Weissig H, Shindyalov IN, Bourne PE. The Protein Data Bank. Nucleic Acids Res. 2000; 28:235-42. https://doi.org/10.1093/nar/28.1.235 PMID: 10592235

27. Chan KK, Yao TJ, Jones B, Zhao JF, Ma FK, Leung CY, Lau SK, Yip MW, Ngan HY. The use of Chinese herbal medicine to improve quality of life in women undergoing chemotherapy for ovarian cancer: a double-blind placebo-controlled randomized trial with immunological monitoring. Ann Oncol. 2011; 22:2241-9.

https://doi.org/10.1093/annonc/mdq749 PMID:21355071

28. Parekh HS, Liu G, Wei MQ. A new dawn for the use of traditional Chinese medicine in cancer therapy. Mol Cancer. 2009; 8:21. https://doi.org/10.1186/1476-4598-8-21 PMID:19298677

29. Colunga Biancatelli RML, Berrill M, Catravas JD, Marik PE. Quercetin and Vitamin C: An Experimental, Synergistic Therapy for the Prevention and Treatment of SARS-CoV-2 Related Disease (COVID-19). Front Immunol. 2020; 11:1451.

https://doi.org/10.3389/fimmu.2020.01451 PMID:32636851

30. Russo M, Spagnuolo C, Tedesco I, Bilotto S, Russo GL. The flavonoid quercetin in disease prevention and therapy: facts and fancies. Biochem Pharmacol. 2012; 83:6-15.

https://doi.org/10.1016/i.bcp.2011.08.010 PMID:21856292

31. Massi A, Bortolini O, Ragno D, Bernardi T, Sacchetti G, Tacchini M, De Risi C. Research Progress in the Modification of Quercetin Leading to Anticancer Agents. Molecules. 2017; 22:1270.

https://doi.org/10.3390/molecules22081270 PMID:28758919

32. Reyes-Farias M, Carrasco-Pozo C. The Anti-Cancer Effect of Quercetin: Molecular Implications in Cancer Metabolism. Int J Mol Sci. 2019; 20:3177. https://doi.org/10.3390/ijms20133177 PMID:31261749

33. Tang SM, Deng XT, Zhou J, Li QP, Ge XX, Miao L. Pharmacological basis and new insights of quercetin action in respect to its anti-cancer effects. Biomed Pharmacother. 2020; 121:109604.

https://doi.org/10.1016/i.biopha.2019.109604 PMID: 31733570

34. Sharma H, Sen S, Singh N. Molecular pathways in the chemosensitization of cisplatin by quercetin in human head and neck cancer. Cancer Biol Ther. 2005; 4:949-55.

https://doi.org/10.4161/cbt.4.9.1908

PMID:16082193

35. de Paula Rodrigues R, Tini IR, Soares CP, da Silva NS. Effect of photodynamic therapy supplemented with quercetin in HEp-2 cells. Cell Biol Int. 2014; 38:716-22. 
https://doi.org/10.1002/cbin.10251

PMID:24470266

36. Bądziul D, Jakubowicz-Gil J, Paduch R, Głowniak K, Gawron A. Combined treatment with quercetin and imperatorin as a potent strategy for killing HeLa and Hep-2 cells. Mol Cell Biochem. 2014; 392:213-27. https://doi.org/10.1007/s11010-014-2032-4 PMID:24682729

37. Lane D, Levine A. p53 Research: the past thirty years and the next thirty years. Cold Spring Harb Perspect Biol. 2010; 2:a000893. https://doi.org/10.1101/cshperspect.a000893 PMID:20463001

38. Zhou G, Liu Z, Myers JN. TP53 Mutations in Head and Neck Squamous Cell Carcinoma and Their Impact on Disease Progression and Treatment Response. J Cell Biochem. 2016; 117:2682-92.

https://doi.org/10.1002/jcb.25592 PMID:27166782

39. Poeta ML, Manola J, Goldenberg D, Forastiere A, Califano JA, Ridge JA, Goodwin J, Kenady D, Saunders J, Westra W, Sidransky D, Koch WM. The Ligamp TP53 Assay for Detection of Minimal Residual Disease in Head and Neck Squamous Cell Carcinoma Surgical Margins. Clin Cancer Res. 2009; 15:7658-65. https://doi.org/10.1158/1078-0432.CCR-09-1433 PMID:19996217

40. Clemente-Soto AF, Salas-Vidal E, Milan-Pacheco C, Sánchez-Carranza JN, Peralta-Zaragoza O, GonzálezMaya L. Quercetin induces G2 phase arrest and apoptosis with the activation of p53 in an E6 expression-independent manner in HPV-positive human cervical cancer-derived cells. Mol Med Rep. 2019; 19:2097-106.

https://doi.org/10.3892/mmr.2019.9850 PMID:30664221

41. Kozaki K, Imoto I, Pimkhaokham A, Hasegawa S, Tsuda $\mathrm{H}$, Omura $\mathrm{K}$, Inazawa J. PIK3CA mutation is an oncogenic aberration at advanced stages of oral squamous cell carcinoma. Cancer Sci. 2006; 97:1351-8. https://doi.org/10.1111/j.1349-7006.2006.00343.x PMID:17052259

42. Chan $\mathrm{CY}$, Lien $\mathrm{CH}$, Lee MF, Huang CY. Quercetin suppresses cellular migration and invasion in human head and neck squamous cell carcinoma (HNSCC). Biomedicine (Taipei). 2016; 6:15. https://doi.org/10.7603/s40681-016-0015-3 PMID:27510965

43. Chung $\mathrm{CH}$, Ely $\mathrm{K}$, McGavran L, Varella-Garcia $\mathrm{M}$, Parker J, Parker N, Jarrett C, Carter J, Murphy BA, Netterville J, Burkey BB, Sinard R, Cmelak A, et al. Increased epidermal growth factor receptor gene copy number is associated with poor prognosis in head and neck squamous cell carcinomas. J Clin Oncol. 2006; 24:4170-6.

https://doi.org/10.1200/JCO.2006.07.2587

PMID:16943533

44. Huang YH, Chang CY, Kuo YZ, Fang WY, Kao HY, Tsai ST, Wu LW. Cancer-associated fibroblast-derived interleukin-1 $\beta$ activates protumor C-C motif chemokine ligand 22 signaling in head and neck cancer. Cancer Sci. 2019; 110:2783-93.

https://doi.org/10.1111/cas.14135

PMID:31325403

45. Chen F, Zheng A, Li F, Wen S, Chen S, Tao Z. Screening and identification of potential target genes in head and neck cancer using bioinformatics analysis. Oncol Lett. 2019; 18:2955-66.

https://doi.org/10.3892/ol.2019.10616

PMID:31452775

46. Oliveira-Paula GH, Lacchini R, Tanus-Santos JE. Endothelial nitric oxide synthase: From biochemistry and gene structure to clinical implications of NOS3 polymorphisms. Gene. 2016; 575:584-99.

https://doi.org/10.1016/i.gene.2015.09.061 PMID:26428312

47. Cooke GE, Doshi A, Binkley PF. Endothelial nitric oxide synthase gene: prospects for treatment of heart disease. Pharmacogenomics. 2007; 8:1723-34. https://doi.org/10.2217/14622416.8.12.1723 PMID: 18086002

48. Choi JY, Barlow WE, Albain KS, Hong CC, Blanco JG, Livingston RB, Davis W, Rae JM, Yeh IT, Hutchins LF, Ravdin PM, Martino S, Lyss AP, et al. Nitric oxide synthase variants and disease-free survival among treated and untreated breast cancer patients in a Southwest Oncology Group clinical trial. Clin Cancer Res. 2009; 15:5258-66.

https://doi.org/10.1158/1078-0432.CCR-09-0685 PMID:19671875

49. Marisi G, Petracci E, Raimondi F, Faloppi L, Foschi FG, Lauletta $G$, lavarone $M$, Canale M, Valgiusti M, Neri LM, Ulivi P, Orsi G, Rovesti G, et al. ANGPT2 and NOS3 Polymorphisms and Clinical Outcome in Advanced Hepatocellular Carcinoma Patients Receiving Sorafenib. Cancers (Basel). 2019; 11:1023. https://doi.org/10.3390/cancers11071023 PMID:31330833

50. Sonveaux P, Brouet A, Havaux X, Grégoire V, Dessy C, Balligand $\mathrm{J}$, Feron $O$. Irradiation-induced angiogenesis through the up-regulation of the nitric oxide pathway: implications for tumor radiotherapy. Cancer Res. 2003; 63:1012-9.

PMID: $\underline{12615716}$ 
51. Yanar K, Çakatay U, Aydın S, Verim A, Atukeren P, Özkan NE, Karatoprak K, Cebe T, Turan S, Ozkök E, Korkmaz G, Cacına C, Küçükhüseyin O, Yaylım i. Relation between Endothelial Nitric Oxide Synthase Genotypes and Oxidative Stress Markers in Larynx Cancer. Oxid Med Cell Longev. 2016; 2016:4985063. https://doi.org/10.1155/2016/4985063 PMID:26682008

52. Guo MF, Dai YJ, Gao JR, Chen PJ. Uncovering the Mechanism of Astragalus membranaceus in the Treatment of Diabetic Nephropathy Based on Network Pharmacology. J Diabetes Res. 2020; 2020:5947304.

https://doi.org/10.1155/2020/5947304

PMID:32215271

53. Sohn TA, Bansal R, Su GH, Murphy KM, Kern SE. Highthroughput measurement of the Tp53 response to anticancer drugs and random compounds using a stably integrated Tp53-responsive luciferase reporter. Carcinogenesis. 2002; 23:949-57. https://doi.org/10.1093/carcin/23.6.949 PMID:12082016

54. Psyrri A, Yu Z, Weinberger PM, Sasaki C, Haffty B, Camp R, Rimm D, Burtness BA. Quantitative determination of nuclear and cytoplasmic epidermal growth factor receptor expression in oropharyngeal squamous cell cancer by using automated quantitative analysis. Clin Cancer Res. 2005; 11:5856-62. https://doi.org/10.1158/1078-0432.CCR-05-0420 PMID:16115926
55. Martini M, De Santis MC, Braccini L, Gulluni F, Hirsch E. PI3K/AKT signaling pathway and cancer: an updated review. Ann Med. 2014; 46:372-83.

https://doi.org/10.3109/07853890.2014.912836 PMID:24897931

56. Xu W, Yang Z, Lu N. A new role for the PI3K/Akt signaling pathway in the epithelial-mesenchymal transition. Cell Adh Migr. 2015; 9:317-24. https://doi.org/10.1080/19336918.2015.1016686 PMID:26241004

57. Tang T, Xiao ZY, Shan G, Lei HB. Descending-SHIP2mediated radiosensitivity enhancement through $\mathrm{PI3K} / \mathrm{Akt}$ signaling pathway in laryngeal squamous cell carcinoma. Biomed Pharmacother. 2019; 118:109392.

https://doi.org/10.1016/j.biopha.2019.109392

PMID:31545285

58. Ye D, Zhou C, Deng H, Lin L, Zhou S. MicroRNA-145 inhibits growth of laryngeal squamous cell carcinoma by targeting the PI3K/Akt signaling pathway. Cancer Manag Res. 2019; 11:3801-12. https://doi.org/10.2147/CMAR.S199291 PMID:31118798 


\section{SUPPLEMENTARY MATERIALS}

\section{Supplementary Figure}

A
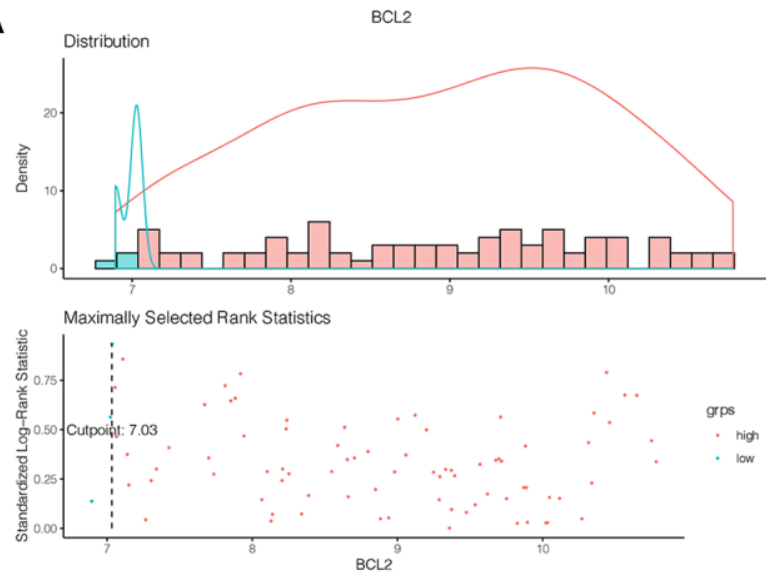

B
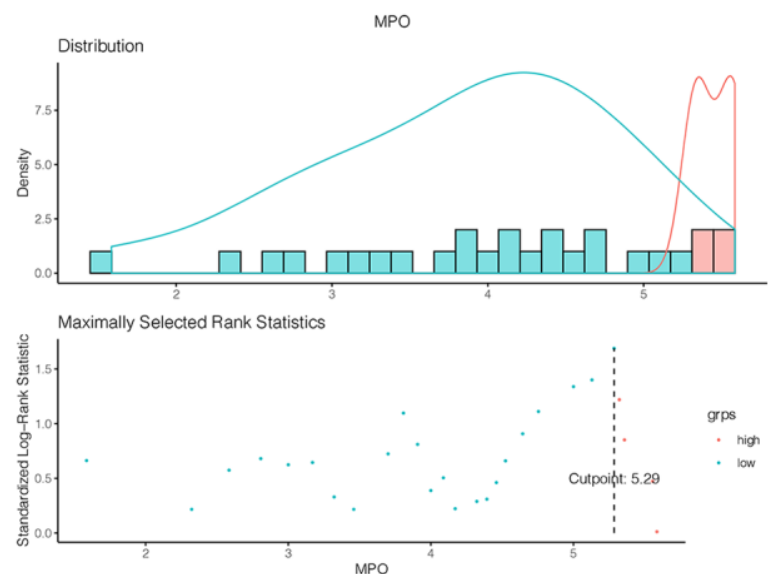

C
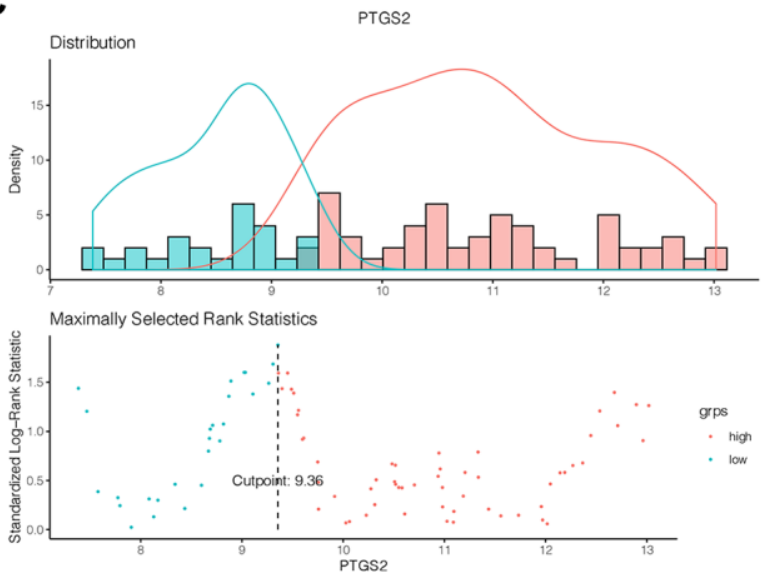
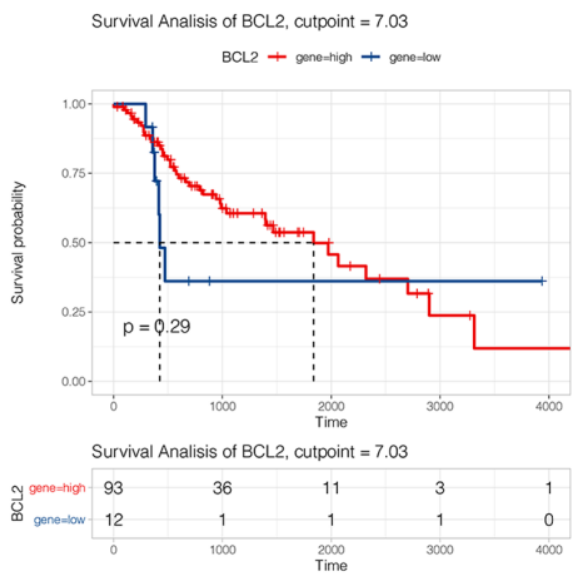

Survival Analisis of MPO, cutpoint $=5.29$

$\mathrm{MPO}+$ gene-high + gane-10

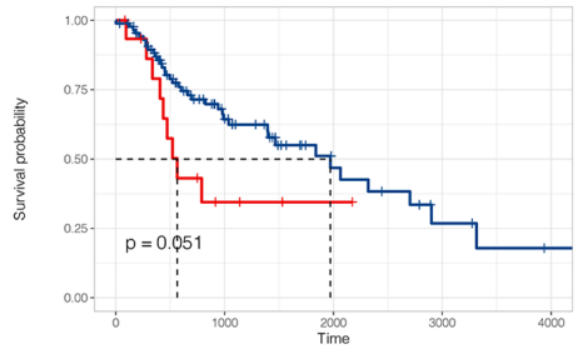

Survival Analisis of MPO, cutpoint $=5.29$

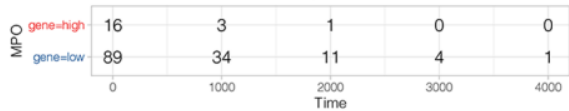

Survival Analisis of PTGS2, cutpoint $=9.36$

PTGS2 + gene-tigh + gene-10w

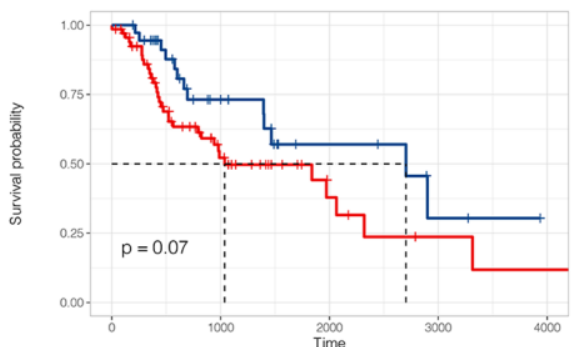

Survival Analisis of PTGS2, cutpoint $=9.36$

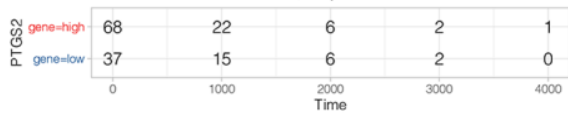

Supplementary Figure 1. Survival analysis of three target genes of Baiying Qinghou decoction using a TCGA dataset. The optimal cutoff value of each gene was calculated to stratify all patients into high- and low-expression groups (left). BCL2 (A), MPO (B), and PTGS2 (C) all were not related to the prognosis of HNSCC patients ( $P>0.05$; right). Abbreviations: HNSCC: head and neck squamous cell carcinoma; TCGA: The Cancer Genome Atlas. 


\section{Supplementary Table}

Supplementary Table 1. The list of target proteins of key active components in Baiying Qinghou decoction.

\begin{tabular}{|c|c|c|c|}
\hline Target proteins & Gene symbol & Target proteins & Gene symbol \\
\hline Prostaglandin $\mathrm{G} / \mathrm{H}$ synthase 1 & PTGS1 & Chymotrypsinogen B & CTRB1 \\
\hline Estrogen receptor & ESR1 & Beta-1 adrenergic receptor & ADRB1 \\
\hline Prostaglandin $\mathrm{G} / \mathrm{H}$ synthase 2 & PTGS2 & Tumor necrosis factor & CD40LG \\
\hline Heat shock protein HSP 90 & HSP90AA1 & Interleukin-6 & IL6 \\
\hline mRNA of PKA Catalytic Subunit C-alpha & PRKACA & Cellular tumor antigen p53 & TP53 \\
\hline Beta-lactamase & LACTBL1 & Interstitial collagenase & MMP1 \\
\hline Progesterone receptor & PGR & C-C motif chemokine 2 & CCL2 \\
\hline Mineralocorticoid receptor & $\mathrm{NR} 3 \mathrm{C} 2$ & Prostaglandin E2 receptor EP3 subtype & PTGER3 \\
\hline Glucocorticoid receptor & $\mathrm{NR} 3 \mathrm{C} 1$ & Acetylcholinesterase & ACHE \\
\hline Carbonic anhydrase II & CA2 & Rhodopsin & RHO \\
\hline Calmodulin & PCP4 & Ferrichrome-iron receptor & FHUA \\
\hline $\begin{array}{l}\text { Phosphatidylinositol-4,5-bisphosphate 3-kinase catalytic } \\
\text { subunit, gamma isoform }\end{array}$ & PIK3CG & Vascular endothelial growth factor A & VEGFA \\
\hline Nitric oxide synthase, inducible & NOS2 & Cell division control protein 2 homolog & CDK1 \\
\hline Thrombin & SERPIND1 & Myeloperoxidase & MPO \\
\hline Potassium voltage-gated channel subfamily $\mathrm{H}$ member 2 & $\mathrm{KCNH} 2$ & Aryl hydrocarbon receptor & AHR \\
\hline Androgen receptor & AR & Cytochrome c & CYCS \\
\hline Sodium channel protein type 5 subunit alpha & SCN5A & Egl nine homolog 1 & EGLN1 \\
\hline Coagulation factor $\mathrm{Xa}$ & F7 & Proto-oncogene serine/threonine-protein kinase Pim-1 & PIM1 \\
\hline Nitric-oxide synthase, endothelial & NOS3 & Cyclin-A2 & CCNA2 \\
\hline Alpha-1B adrenergic receptor & ADRA1B & Peroxisome proliferator activated receptor delta & PPARD \\
\hline Beta-2 adrenergic receptor & ADRB2 & Heme oxygenase 1 & HMOX1 \\
\hline DNA topoisomerase II & TOP2B & $\mathrm{NAD}(\mathrm{P}) \mathrm{H}$ dehydrogenase [quinone] 1 & NQO1 \\
\hline Estrogen receptor beta & ESR2 & Epidermal growth factor receptor & EGFR \\
\hline Dipeptidyl peptidase IV & DPP4 & $72 \mathrm{kDa}$ type IV collagenase & MMP2 \\
\hline Glycogen phosphorylase, muscle form & PYGM & Mitogen-activated protein kinase 1 & MAPK1 \\
\hline Glycogen synthase kinase- 3 beta & GSK3B & Retinoblastoma-associated protein & RB1 \\
\hline Cell division protein kinase 2 & CDK2 & Cell division protein kinase 4 & CDK4 \\
\hline Serine/threonine-protein kinase Chk1 & CHEK1 & Xanthine dehydrogenase/oxidase & $\mathrm{XDH}$ \\
\hline Ig gamma-1 chain $\mathrm{C}$ region & IGHG1 & DNA topoisomerase 1 & TOP1 \\
\hline Trypsin-1 & PRSS1 & Amyloid beta A4 protein & APBA3 \\
\hline Nuclear receptor coactivator 2 & NCOA2 & Caspase-7 & CASP7 \\
\hline Nuclear receptor coactivator 1 & NCOA1 & Interleukin-2 & IL2 \\
\hline Calcium-activated potassium channel subunit alpha 1 & KCNMA1 & Interferon gamma & IFNG \\
\hline Peroxisome proliferator activated receptor gamma & PPARG & Glutathione S-transferase P & GSTP1 \\
\hline Retinoic acid receptor RXR-alpha & RXRA & Insulin receptor & INSR \\
\hline CGMP-inhibited 3',5'-cyclic phosphodiesterase A & PDE3A & Hepatocyte growth factor receptor & MET \\
\hline Alpha-1D adrenergic receptor & ADRA1D & Stromelysin-1 & MMP3 \\
\hline Mitogen-activated protein kinase 14 & MAPK14 & Pro-epidermal growth factor & EGF \\
\hline Alpha-1 A adrenergic receptor & ADRA1D & NADPH--cytochrome P450 reductase & POR \\
\hline Sodium-dependent serotonin transporter & SLC6A4 & Ornithine decarboxylase & ODC1 \\
\hline Amine oxidase [flavin-containing] B & MAOB & Superoxide dismutase $[\mathrm{Cu}-\mathrm{Zn}]$ & SOD1 \\
\hline Neuronal acetylcholine receptor protein, alpha-7 chain & CHRNA7 & $78 \mathrm{kDa}$ glucose-regulated protein & HSPA5 \\
\hline cAMP-dependent protein kinase inhibitor alpha & PKIA & Acetyl-CoA carboxylase 1 & ACACA \\
\hline
\end{tabular}


Cytochrome P450-cam

Dopamine D1 receptor

Muscarinic acetylcholine receptor M3

Muscarinic acetylcholine receptor M1

Gamma-aminobutyric-acid receptor alpha-2 subunit

Muscarinic acetylcholine receptor M4

5 -hydroxytryptamine $2 \mathrm{~A}$ receptor

Gamma-aminobutyric-acid receptor alpha-5 subunit

Gamma-aminobutyric-acid receptor alpha-3 subunit

Muscarinic acetylcholine receptor M2

Neuronal acetylcholine receptor subunit alpha-2

Mu-type opioid receptor

Gamma-aminobutyric acid receptor subunit alpha-1

Apoptosis regulator $\mathrm{Bcl}-2$

Transcription factor AP-1

Serum paraoxonase/arylesterase 1

Microtubule-associated protein 2

Coagulation factor VII

Vascular endothelial growth factor receptor 2

Alcohol dehydrogenase 1C

Alpha-2A adrenergic receptor

Sodium-dependent noradrenaline transporter

Sodium-dependent dopamine transporter

Aldose reductase

Urokinase-type plasminogen activator

Leukotriene A-4 hydrolase

\begin{tabular}{|c|c|c|}
\hline CYP101A1 & Cytochrome P450 3A4 & CYP3A4 \\
\hline DRD1 & Cytochrome P450 1A2 & CYP1A2 \\
\hline CHRM3 & Tissue factor & F3 \\
\hline CHRM1 & Gap junction alpha-1 protein & GJA1 \\
\hline GABRA2 & Interleukin-1 beta & IL1B \\
\hline CHRM4 & E-selectin & SELE \\
\hline HTR2A & Vascular cell adhesion protein 1 & VCAM1 \\
\hline GABRA5 & Estrogen sulfotransferase & SULT1E1 \\
\hline GABRA3 & Maltase-glucoamylase, intestinal & MGAM \\
\hline CHRM2 & Tissue-type plasminogen activator & PLAT \\
\hline CHRNA2 & Thrombomodulin & THBD \\
\hline OPRM1 & Collagen alpha-1(I) chain & COL1A1 \\
\hline GABRA1 & Arachidonate 5-lipoxygenase & ALOX5 \\
\hline BCL2 & Collagen alpha-1(III) chain & COL3A1 \\
\hline JUN & DNA gyrase subunit B & GYRB \\
\hline PON1 & Prostatic acid phosphatase & ACPP \\
\hline MAP2 & Cathepsin D & CTSD \\
\hline F7 & Glutathione S-transferase $\mathrm{Mu} 1$ & GSTM1 \\
\hline KDR & Glutathione S-transferase $\mathrm{Mu} 2$ & GSTM2 \\
\hline ADH1C & Stromelysin-2 & MMP10 \\
\hline ADRA2A & Fatty acid synthase & FASN \\
\hline SLC6A2 & Catalase & CAT \\
\hline SLC6A3 & Cytosolic phospholipase A2 & PLA2G4A \\
\hline AKR1B1 & Serine/threonine-protein kinase mTOR & MTOR \\
\hline PLAU & Amine oxidase [flavin-containing] A & MAOA \\
\hline LTA4H & & \\
\hline
\end{tabular}

